\title{
Patrimonio urbano y alojamientos turísticos en Cienfuegos (Cuba)
}

\section{Urban Heritage and Tourist Accommodation in Cienfuegos (Cuba)}

\author{
Mercedes Rodríguez-Rodríguez* \\ Universidad de Las Palmas de Gran Canaria \\ https://orcid.org/0000-0003-1015-2027 \\ mercedes.rodriguez@ulpgc.es \\ Manuel Ramón González-Herrera \\ Universidad Autónoma de Ciudad Juárez \\ http:// orcid.org/0000-0002-2104-4702 \\ manuel.gonzalez@uacj.mx \\ Josefina Domínguez-Mujica \\ Universidad de Las Palmas de Gran Canaria \\ http:/ / orcid.org/0000-0001-7460-5553 \\ josefina.dominguezmujica@ulpgc.es
}

Recibido: 18/03/2020; Revisado: 13/05/2020; Aceptado: 25/06/2020

\begin{abstract}
Resumen
La conservación de las ciudades cubanas Patrimonio de la Humanidad se basa en iniciativas públicas que afrontan la rehabilitación de inmuebles de reconocido valor arquitectónico, al mismo tiempo que muchos otros edificios mantienen sus características originales gracias a la inversión de pequeños emprendedores turísticos. El análisis de estas intervenciones en Cienfuegos, a partir de un riguroso trabajo de campo, es el objetivo del artículo. Para ello, se ha puesto en relación la ubicación y características de los hostales según las etapas de desarrollo urbano y las tipologías arquitectónicas prerrevolucionarias, lo que confiere un indiscutible valor patrimonial a la llamada Perla del Sur.
\end{abstract}

Palabras clave: Ciudad patrimonio de la Humanidad, patrimonio urbano, inversión turística, Cienfuegos, Cuba.

*Autor de correspondencia / Corresponding author.

Copyright: () 2021 ULPGC. Este es un artículo de acceso abierto distribuido bajo los términos de la licencia Creative Commons Atribución-NoComercial-SinDerivar (by-nc-nd) Spain 3.0. 


\begin{abstract}
The conservation of Cuban World Heritage cities is based on public initiatives geared towards the restoration of properties with recognized architectural value, while many other buildings maintain their original characteristics thanks to the investment of smaller touristic entrepreneurs. The aim of this article, following rigorous fieldwork, is the analysis of such interventions in Cienfuegos. To that end, the location and characteristics of these hostels have been contextualized according to stages of urban development and pre-revolutionary architectural typologies, all of which signals the unquestionable heritage value of the so-called Pearl of the South.
\end{abstract}

Key words: World Heritage City, Urban Heritage, Touristic Investment, Cienfuegos, Cuba.

\title{
1. INTRODUCCIÓN
}

Las modalidades de turismo cultural y patrimonial han registrado un importante impulso en los últimos años, particularmente en ciudades Patrimonio de la Humanidad, las cuales resultan atractivas para los visitantes por los valores tangibles e intangibles que encierran (LÓPEZ-GUZMÁN et al., 2017; TROITIÑO- VINUESA, 2018). En tales casos, la promoción turística se basa en una convincente propuesta de valor, de forma tal que contribuye a la formación de experiencias memorables, sustentadas en los sentimientos y motivaciones del visitante, para facilitar una óptima comprensión cognitiva y una favorable relación afectiva con el patrimonio de los destinos que se visitan. Esta orientación origina que los perfiles turísticos se diversifiquen y reconstruyan de forma acelerada (RICALDE, 2019). ${ }^{1}$ Como antecedente al estudio de esta temática, es necesario precisar que:

Los términos turismo y patrimonio encierran un debate sobre sus alcances e implicancias. [Se acepta que] (...) el concepto turismo patrimonial constituye un binomio que ayuda a fijar posición sobre una manera de entender el uso social de los bienes. [Concebido de esta forma, el turismo patrimonial es el] (...) tipo de turismo que se basa y promueve el conocimiento, la exploración y la promoción -en el sentido de desarrollo- del patrimonio como construcción social, ayudando a su preservación y pone el énfasis en la cultura viva de los territorios, anclándose en el concepto de espíritu de lugar, [lo cual significa] exponer, debatir y repensar la manera en que se desarrollan los llamados productos turísticos y específicamente los que usufructúan la categoría patrimonio en cualquiera de sus alcances (RIVERO y KunA, 2013: 1).

En este contexto se enmarca el estudio desarrollado acerca de la ciudad de Cienfuegos (Cuba). En él nos fijamos como principal objetivo de investigación la caracterización del desarrollo turístico de Cuba desde la perspectiva de las iniciativas turísticas locales. Como objetivos secundarios pretendemos analizar las iniciativas turísticas locales en Cienfuegos con la evolución urbana de la etapa prerrevolucionaria (anterior al 1959, año del triunfo de la Revolución cubana); interpretar las características tipológicas de los inmuebles a la luz de los estilos arquitectónicos propios del siglo XIX y de la primera mitad del xx; destacar el interés de la conservación de los inmuebles objeto de estudio, dada su riqueza arquitectónica; y, por último, reflexionar sobre el papel que puede jugar la

1 Ricalde, N., 2019: «¿Qué busca el Turismo Naranja?», en Entorno Turístico [en línea]. Disponible en: https://www.entornoturistico.com/busca-turismo-naranja/?_gl=1*e9vup4*_ga*YW1wLUVFT3ZT dVRwYkRMR2pmMlA4NXJEWVFDRndaQlgxYUlBTlpoUkV1OUJM QXIsZldoZzlhanlnY2tFT2JSRjVJNOU [Consulta: 18/03/2020]. 
promoción turística en la conservación patrimonial en Cuba, una situación particular, que contrasta con una literatura abundante para los países europeos y otros desarrollados, que defiende el perjuicio del overtourism en muchos centros históricos. Todo ello permite que el estudio de Cienfuegos sea útil para reconocer, a través de un caso local, la diversidad de situaciones que encierran las potencialidades de desarrollo turístico cuando se aúna Patrimonio e iniciativas locales de emprendimiento, máxime si tenemos en cuenta la particular regulación jurídico-administrativa cubana en esta materia.

En correspondencia con estos objetivos, el artículo se estructura de la siguiente forma. Tras esta introducción, se realiza una aproximación al estado del arte, referido a la promoción turística en Ciudades Patrimonio de la Humanidad; a continuación, se presentan las fuentes y metodología de la investigación; en la cuarta sección se abordan los resultados, es decir, el estudio de las iniciativas turísticas locales en Cuba. En cuanto a la discusión de resultados, un quinto apartado está dedicado a los aspectos más significativos de la geografía e historia de la ciudad de Cienfuegos como ciudad patrimonial y a sus implicaciones, una visión que se complementa con la del siguiente epígrafe, en el que se ofrece un análisis geográfico y patrimonial de las intervenciones turísticas privadas en dicha ciudad. Ambos anteceden a las conclusiones y a las referencias bibliográficas del estudio.

\section{LA PROMOCIÓN TURÍSTICA EN CIUDADES PATRIMONIO DE LA HUMANIDAD. ESTADO DEL ARTE}

Las bases conceptuales y metodológicas para los estudios del turismo patrimonial se sustentan en los avances registrados durante las últimas décadas en el marco del turismo como disciplina científica (JAFARI, 2005). Así, las principales tendencias actuales corresponden a la perspectiva crítica (CAMARGO y SÁNCHEZ, 2016; ${ }^{2}$ Young et al., 2017; CAÑADA y MurRAY, 2019), al overtourism (SERAPHIN et al, 2020), y a la postdisciplinariedad turística que, a su vez, encierra el turismo sostenible e inteligente (MunAR et al., 2016; ColEs et al., 2016). En consecuencia, estos enfoques se están extendiendo progresivamente hacia las modalidades del turismo cultural y patrimonial.

Para tales fines, el análisis integrado de los destinos turísticos sobre bases sostenibles deberá constituirse en estrategia de gestión preventiva ante situaciones de deterioro del patrimonio, ya que muchos espacios turísticos sufren impactos adversos, que terminan afectando a su valor conservativo y a su atractividad turística. Por tal razón, debe asumirse un posicionamiento crítico reflexivo con respecto a la conceptualización del desarrollo en destinos turísticos patrimoniales, basado en el análisis de los modelos de desarrollo implantados. No obstante, cabe destacar que se reconoce una «falta de metodologías sistemáticas de evaluación, para considerar adecuadamente la brecha entre el desarrollo urbano sostenible y la conservación del patrimonio cultural» (GuZMÁN et al., 2017: 196).

2 Camargo, B.; SÁnchez, I., 2016): «Educators' Perceptions and Incorporation of Critical Perspectives in Tourism Programs: The Case of Mexico», en 9th Tourism Education Futures Initiative Conference (TEFI9), Thompson Rivers University [en línea]. Disponible en: https://digitalcommons. library.tru.ca/tefi/?utm_source=digitalcommons.library.tru.ca $\% 2$ Ftefi $\% 2$ Ftefi9 $\% 2$ Fday $1 \% 2$ F $11 \& u$ tm_medium=PDF\&utm_campaign=PDFCoverPages [Consulta: 18/03/2020]. 
En particular, la dimensión geoespacial-territorial del turismo y los procesos de producción del espacio turístico en destinos urbanos patrimoniales están directamente relacionados con las actuaciones que promueven su puesta en valor turístico, la apropiación social, y su uso productivo (MATUs et al., 2019). En consecuencia, es preciso perfeccionar los mecanismos de gestión de los recursos en los destinos patrimoniales, aplicando enfoques alternativos y creativos, con el fin de realizar propuestas constructivas que presten mayor atención a los sitios Patrimonio de la Humanidad; por ende, deberán proyectarse estrategias que promuevan la participación social a través de procedimientos vinculantes de orden público/privado-comunitario, en los que se involucre la planificación participativa, y se potencien estructuras de gestión con capacidad efectiva para llevar a cabo propuestas integradas.

En opinión de TroitiÑo-VINUESA y Troitiño-TORRALBA (2016: 9-15), «el turismo es, sin duda, una de las actividades que quizás mejor contribuya a visualizar la dimensión económica del patrimonio y a despertar CIERTA preocupación por su conservación» [pues]:

El patrimonio cultural como fuente de riqueza abre nuevas vías de acción para caminar hacia un desarrollo turístico sostenible, basado en un uso responsable del mismo como garantía de conservación (...) [por lo que el] (...) patrimonio territorial, lejos de bloquear el desarrollo económico y social, es un poderoso aliado y genera nuevas expectativas económicas y sociales, especialmente en el sector turístico.

\section{En un trabajo posterior, TROITIÑO-VINUESA (2018: 1) expone que:}

A pesar de la contribución del turismo a la recuperación y revitalización de los sitios del Patrimonio de la Humanidad en España, se ha producido una excesiva e incontrolada presión, [ante la cual] resulta urgente controlarlo y canalizarlo en función de las necesidades de la conservación, porque estas ciudades tienen adquirido el voluntario e ineludible compromiso de preservar un patrimonio con reconocido valor universal excepcional.

En esta misma línea, BANDARIN (2017) $)^{3}$ plantea que «el turismo es un recurso clave para las comunidades locales y para la conservación del patrimonio (...) [y] es crucial para brindar estabilidad social e identidad [por lo que] vincular la cultura y el turismo en el proceso del desarrollo sostenible resulta vital para alcanzar los Objetivos de Desarrollo Sostenible».

Como se aprecia en la conceptualización anterior, el turismo puede ser un importante factor de desarrollo económico, social y local en diferentes contextos, de tal forma que el vínculo entre cultura y turismo es innegable. Según estudios recientes, «el 37\% del turismo mundial tiene motivaciones culturales (...), sin embargo, también puede afectar a los sitios de manera negativa» (UNESCO, $2017)^{4}$, razón por la cual es necesario tomar en consideración las convergencias

3 BANDARIN, F., 2017: La OMT y la UNESCO: turismo y cultura para impulsar los ODS [en línea]. Disponible en: https://121.mx/la-omt-y-la-unesco-turismo-y-cultura-para-impulsar-los-ods [Consulta: 18/03/2020].

4 UNESCO, 2017: «Turismo - entre la oportunidad y la amenaza», en Patrimonio Cultural sub-acuático [en línea]. Disponible en: http://www.unesco.org/new/es/culture/themes/underwater-culturalheritage/protection/threats/tourism [Consulta: 18/03/2020]. 
y divergencias entre el patrimonio cultural y el turismo. Según TRESSERRAS (2015):

El turismo naranja es un turismo sostenible y generador de desarrollo cultural, económico y social a partir de la gestión turística responsable del patrimonio cultural, la producción artística y las industrias culturales y creativas (...) contribuyendo a generar oportunidades para la comunidad local a partir de su identidad y mediante la configuración de destinos naranja, territorios o clústeres turísticos con identidad cultural. [A la vez plantea que] el destino naranja debe disponer de un portafolio de productos derivados de la acción creativa de la comunidad local, o de la interacción de ésta con el turista. Consiste en un destino con un imaginario, un(os) icono(s), con una marca, un precio y un lugar en el mercado, con una comunidad que participa, se identifica y ejerce de anfitriona, y que mantiene durante una gran parte del año un flujo de visitantes y turistas lo suficientemente numerosos como para convertir esta actividad en una de las bases de su economía. ${ }^{5}$

\section{Complementa estos conceptos RICALDE (2019) cuando plantea que:}

El turismo naranja propone qué experiencias no se debe perder un visitante para lograr conectar con los habitantes de ese lugar y sentirse integrado dentro de la cultura local. Así es que esta nueva tendencia (...) constituye una forma diferente de entender el turismo cultural pues pasar una tarde en un mercado, asistir a un festival de música local o acudir a una actividad de ocio propia de la gente del destino ha dejado de ser sólo para los locales y ha empezado a formar parte de la nueva oferta de un destino (...) y que como gran ventaja ofrece además de la diversificación de la oferta, la atemporalidad.

A nivel internacional se ha registrado un fuerte impacto del turismo sobre el patrimonio, provocando fenómenos extremos de masificación o turistificación (overtourism), lo que ha puesto en riesgo los valores culturales y su atractividad. Tales son los casos de destinos como Venecia, que recibe más de 30 millones de visitantes al año, Ibiza considerada el segundo destino más saturado a nivel mundial, las islas griegas de Santorini y Mykonos, o Dubrovnik en Croacia. Tal situación ha conllevado a que destinos como Los Países Bajos hayan retirado el cartel "Yo soy Ámsterdam» para detener la marea del turismo masivo (MACK, 2019). ${ }^{6}$ En lugares Patrimonio de la Humanidad la masificación sigue creciendo, porque los destinos se promocionan sin gestionar convenientemente los flujos de visitantes de acuerdo a su capacidad de carga; éstos son los casos de la Pirámide de Guiza, en Egipto, y Muralla China, con más de 10 millones de visitantes al año; o destinos como Petra, Machu Picchu y Taj Mahal, donde ha sido necesario implementar diversas estrategias para reducir el número de visitantes.

El problema de la saturación turística o turistificación (overtourism) no solo se relaciona con los impactos negativos sobre el patrimonio, sino también con la percepción de calidad, la satisfacción del visitante y sus intenciones futuras.

5 TRESSERRAS, J., 2015: «El turismo naranja: el color del turismo cultural y creativo. Rumbo a una alianza estratégica entre los sectores cultural y turístico», en Hosteltur ODS [en línea]. Disponible en: https://www.hosteltur.com/comunidad/004289_el-turismo-naranja-el-color-del-turismo-culturaly-creativo-rumbo-a-una-alianza-estrategica-entre-los-sectores-cultural-y-turistico.html [Consulta: 18/03/2020].

6 МАСК, B., 2019: «22 lugares que han sido arruinados por el turismo masivo en esta década», en Business Insider [en línea]. Disponible en: https:// www.businessinsider.es/22-lugares-han-sido-arruinados-turismo-masivo-decada-550339 [Consulta: 18/03/2020]. 
«Pero estas experiencias de viaje no van más allá de visitas guiadas, experiencias gastronómicas o representaciones culturales, es decir, carecen de algo fundamental: no ofrecen una experiencia real en el destino (...) [razón por la cual muchas veces] (...) el turista asume una participación contemplativa y/o pasiva» (RICALDE, 2019). En relación con esto, se asume que «la capacidad de carga social percibida por los turistas puede ser definida como el umbral de saturación tras el cual buscan destinos alternativos [en tales casos,] [el] grado de concentración de un destino turístico se relaciona con la experiencia turística [provocando que] (...) el nivel de satisfacción pueda disminuir» (ALMEIDA, 2006: 241).

El caso de Cuba no queda al margen de las tendencias globales mencionadas, dado que es evidente una fuerte orientación de los flujos de visitantes hacia determinadas zonas de gravitación turística, como Trinidad o La Habana Vieja. Por solo citar un ejemplo, la ciudad de Trinidad, cuyo centro histórico fue declarado por la UNESCO en 1998 Patrimonio Mundial, tiene una población de 75.600 habitantes (2015), al tiempo que cuenta con 1.155 plazas turísticas operadas por el Estado y casi tres mil en alojamientos privados, al mismo tiempo que funcionan 99 «paladares» [restaurantes privados] y 850 cafeterías que atienden a los miles de turistas que recibe cada año. ${ }^{7}$ Se trata de uno de los polos turísticos más completos de Cuba, caracterizado por una excelente combinación de propuestas culturales con modalidades de sol y playa, pero dada la concentración de gran parte de los atractivos culturales en el centro urbano, se advierten ya indicadores de masificación turística durante determinadas horas y épocas del año.

El desarrollo turístico internacional acelerado que ha experimentado Cuba durante las últimas décadas ha motivado que académicos, investigadores y gestores se involucren en su estudio. Por esta razón, la producción científica en temas de patrimonio cultural y turismo ha sido prolífica, lo cual ha posicionado favorablemente el papel que tiene el desarrollo turístico para la conservación de las ciudades patrimoniales del país, incorporando temas como la valoración del patrimonio urbano-arquitectónico en su condición de atractivo turístico (CHAOs et al., 2019), el análisis de las ciudades patrimoniales cubanas como producto turístico (PONCE, 2010), la contribución del turismo patrimonial a favor del desarrollo local y regional (CARDET et al., 2017; RODRíGUEZ y CAMACHO, 2017), así como tópicos referidos a lo global, lo local y la sostenibilidad del turismo patrimonial (SALINAS et al., 2018).

De acuerdo con el estudio realizado para el caso cubano por PÉrez GuILARTE (2015: 67), el turismo cultural debe ser concebido «... no solo como las visitas a sitios y monumentos históricos, sino ampliado al conocimiento de la forma de vida y tradiciones de las poblaciones locales». Concluye la misma autora que «Cuba sí es apreciada como un destino cultural, al menos desde la perspectiva del mercado español. Los elementos que la distinguen de otros destinos culturales son la hospitalidad y la amabilidad de su población, además del Centro Histórico de La Habana, su música, baile y modo de vida» (Pérez Guilarte, 2015: 79). En tal sentido, la conservación y revalorización de las ciudades cubanas Patrimonio de la Humanidad puestas en valor turístico, se desarrolla mediante iniciativas públicas que asumen la rehabilitación de inmuebles de gran significación y de reconocido valor arquitectónico, al mismo tiempo que un número considerable

7 Agencia Prensa Latina, 2018: «Trinidad de Cuba, con un gran futuro turístico», en Escambray [en línea]. Disponible en: http:// www.escambray.cu/2018/trinidad-de-cuba-con-un-gran-futuro-turistico [Consulta: 18/03/2020]. 
de edificaciones mantienen sus características originales, debido a la inversión de pequeños emprendedores turísticos locales.

Con el fin de minimizar los impactos adversos sobre el patrimonio, en la planificación turística deberán considerarse con enfoque holístico las características del sistema urbano en lo relativo a su composición, estructura, funcionamiento, y jerarquía, reconociendo elementos representativos como su morfología; las tipologías territoriales, urbanísticas y arquitectónicas; la trama urbana; la estructura funcional; los rasgos tecnológicos; la presencia humana y sus sistemas de referencias -información, señalética, publicidad; así como los significados e identidades culturales. Ello permitirá una mejor valoración de las actividades turísticas de los sitios históricos y arqueológicos; construcciones religiosas, civiles, domésticas, militares, conmemorativas, industriales; instituciones culturales; manifestaciones culturales populares; realizaciones científico técnicas y artísticas; espacios culturales abiertos/cerrados; población anfitriona; infraestructura recreativa; e infraestructura social (CALLIZO, 1991; BOULLón, 1997; ACERENZA, 2000; VALLS, 2004; Organización Mundial del Turismo, 2007; PeArCe, 2013).

De esta manera, el visitante podrá disfrutar de una experiencia memorable en función de: (a) atractivos culturales y cognoscitivos: plazas y plazuelas, parques, museos, sitios históricos, iglesias, galerías de arte, teatros, rutas urbanas y circuitos culturales; (b) atractivos de entretenimiento y diversión con tendencia al ocio activo o participativo: eventos, festividades culturales, medios de transporte originales o inusuales; y (c) atractivos profesionales: recintos feriales, salas de exposiciones. Desde esta perspectiva pueden cubrirse las motivaciones culturales, lúdicas y profesionales de los visitantes, aprovechando la configuración gravitacional turística del espacio urbano a partir de los principales focos turísticos urbanos, los corredores turísticos y sus áreas de influencia.

\section{FUENTES Y METODOLOGÍA DE LA INVESTIGACIÓN}

Además de la documentación legal y de las fuentes consultadas, la investigación sobre las intervenciones turísticas de la iniciativa privada en el ámbito geográfico declarado como Patrimonio de la Humanidad, en Cienfuegos (Cuba), se fundamentó en un exhaustivo trabajo de campo, que se desarrolló en distintas fases. En primer lugar, se realizó un reconocimiento de la localización de los distintos inmuebles dedicados al alojamiento turístico del sector privado (hostales) y se procedió a cartografiar dicha localización en el plano de la ciudad, a partir del sistema de información geográfica ArcGIS. Tras esta etapa observacional, en la que también se realizaron fotografías de las fachadas de los inmuebles, se hizo un inventario mediante una ficha de cada uno de ellos, en la que se hicieron constar sus características tipológicas.

En una segunda etapa, se afrontó una metodología de tipo transversal, basada en la implementación de un cuestionario estructurado, el cual consta de 17 preguntas de tipo cerrado $(84,2 \%)$, elección única $(18 \%)$, elección múltiple (31\%) y escala de Likert (50\%), mediante el cual se midieron 44 variables de tipos nominales, ordinales, y de escala. Para validar la encuesta se utilizó el alfa de Cronbach en cuatro grupos de preguntas y, a pesar de que algunas variables no pudieron ser contrastadas, se puede decir que la encuesta fue correctamente validada (los índices del coeficiente alfa de Cronbach siempre fueron mayores a 
$0,7)$.

La unidad de análisis correspondió a personas, consideradas como sujetos de interés (propietarios y operarios de los hostales e inversionistas del sector inmobiliario residencial), muchos de ellos emigrantes residiendo en el extranjero, aunque ninguno de estos últimos pudo ser encuestado, sólo los propietarios residentes. El valor del tamaño de la población corresponde a aproximadamente 1.000 hostales, y el de la muestra a 122 cuestionarios (95\% de nivel de confianza, precisión de 0,05 y proporción de éxito 0,9). El cuestionario lo respondieron de manera presencial los 150 emprendedores, dueños o administradores de hostales, en los meses de julio y agosto de 2019.

Para la elaboración de este artículo nos centramos en algunas de las respuestas de las encuestas realizadas en la ciudad objeto de estudio, especialmente en aquellas relativas a la antigüedad del inmueble, su tipología arquitectónica y la dimensión del establecimiento (Tabla 1). Ello nos permitió seleccionar determinados hostales en función de su valor patrimonial, con la finalidad de demostrar la siguiente hipótesis: la inversión privada en negocios turísticos juega un papel definitivo en la conservación del patrimonio de la ciudad de Cienfuegos, en Cuba, cuyo centro histórico fue declarado Patrimonio de la Humanidad en 2005.

TABLA 1

Resultado de la encuesta realizada a los propietarios de los hostales

\begin{tabular}{|c|c|c|c|c|c|c|c|c|c|}
\hline \multirow{2}{*}{$\begin{array}{c}\text { Total } \\
\text { encuestas }\end{array}$} & \multicolumn{3}{|c|}{ Antigüedad } & \multicolumn{3}{c|}{ Tipología arquitectónica } & \multicolumn{3}{c|}{$\begin{array}{c}N^{0} \text { de hab. que } \\
\text { renta }\end{array}$} \\
\cline { 2 - 10 } & $\leq 1930$ & $\begin{array}{l}1930- \\
1960\end{array}$ & $>1960$ & Colonial & $\begin{array}{c}\text { Neo- } \\
\text { clásico }\end{array}$ & $\begin{array}{c}\text { Etapa } \\
\text { Revolución }\end{array}$ & $\begin{array}{c}1 \\
\text { hab. }\end{array}$ & $\begin{array}{c}2 \\
\text { hab. }\end{array}$ & $\begin{array}{c}\geq 3 \\
\text { hab. }\end{array}$ \\
\hline 150 & $30 \%$ & $42 \%$ & $28 \%$ & $12 \%$ & $52,7 \%$ & $35,3 \%$ & $8,7 \%$ & $41,3 \%$ & $50,0 \%$ \\
\hline
\end{tabular}

Fuente: Elaboración propia.

\section{EL DESARROLLO TURÍSTICO DE CUBA DESDE LA PERSPECTIVA DE LAS INICIATIVAS LOCALES}

El turismo constituye una prioridad estratégica en el plan de ajustes promovido por el Gobierno de Cuba para renovar el modelo económico socialista, pues representa la segunda actividad que más contribuye a la captación de divisas. En 2019 el destino recibió 4.275 .558 visitantes, lo cual reportó un ingreso de 2.184.602,6 (Miles de CUC), siendo las actividades turísticas de mayor aportación: la gastronomía $(41,1 \%)$, el alojamiento $(26,1 \%)$, el comercio minorista $(12,6 \%)$, y el transporte $(8,1 \%)$. Los principales países emisores hacia Cuba correspondieron a Canadá $(26,3 \%)$, la comunidad cubana residente en el exterior (principalmente Estados Unidos, España, Canadá y México) (14,6\%), y Estados Unidos (11,7\%). ${ }^{8}$

En cuanto a la oferta, la planta alojativa de Cuba está integrada por 73.247

8 ONEI (Oficina Nacional de Estadística e Información), 2020: Turismo Internacional. Indicadores Seleccionados. Enero - diciembre 2019. Edición marzo 2020 [en línea]. Disponible en: http:/ / www.onei.gob. cu/node/14814 [Consulta: 18/03/2020]. 
habitaciones hoteleras operadas por empresas estatales y mixtas con capital extranjero, así como por más de 26.742 habitaciones en casas particulares que ofrecen servicios de alojamiento. En el corto plazo (2020) se prevé la inauguración de 26 nuevos hoteles que dispondrán de 4.100 habitaciones, en tanto que en el largo plazo (hacia el 2030) se tiene proyectado el desarrollo de 741 proyectos turísticos, integrados en 437 de alojamiento, 92 de recreación, 12 desarrollos inmobiliarios vinculados a campos de golf, 29 de turismo de naturaleza, 54 mejoras para el campismo nacional, 32 para náutica recreativa y 82 de apoyo en transportación y almacenamiento. ${ }^{9}$

La apertura de Empresas Turísticas Privadas en Cuba ha estado asociada coyunturalmente a «la más profunda crisis económica de su historia, la cual comenzó a manifestarse desde inicios de la década de 1990» (ANTúNEZ et al., 2013: 3). En consecuencia, se hizo necesaria la reestructuración del modelo económico cubano, el cual refleja los rasgos de «una economía en transición, caracterizada por la evolución desde una actividad centralmente planificada hacia una economía de mercado» (DodDs et al., 2018: 99), proceso al cual están asociadas profundas transformaciones sociales (SACCHETTI, 2011).

En tal escenario, se reconoce el importante rol del turismo como parte de las reformas económicas implementadas (JARIWALA, 2014; DodDs et al., 2018) desde 1995, especialmente por su contribución al fomento de empresas privadas, a los nuevos emprendimientos y al autoempleo. Esta tendencia puede mantenerse, ya que, según pronósticos de la aportación del turismo al PIB cubano, «se producirá un crecimiento anual del 4.9\%, para alcanzar el 12.3\% del PIB en el año 2026» (DoDDs et al., 2018: 99).

Cabe destacar que tales predicciones se originaron en un escenario político y económico anterior más favorable, pues recientemente el Gobierno de Estados Unidos ha declarado un conjunto de medidas hacia Cuba, tales como la limitación de la entrada de cruceros, el anuncio de la cancelación de envíos de remesas por Western Union y la suspensión de los vuelos comerciales a nueve aeropuertos del país, ${ }^{10}$ que repercuten negativamente sobre los indicadores turísticos de este destino.

Las decisiones gubernamentales para el desarrollo formal de las actividades turísticas privadas en Cuba se inscriben en la categoría «Trabajo por Cuenta Propia (TCP)», el cual, a pesar de no tener una conceptualización explícita, representa la participación del sector privado en las actividades de la economía, y en la creación de empresas familiares. Este tipo de trabajo es definido por el Estado como una categoría ocupacional no subordinada a la administración de una entidad laboral, por lo que el trabajador asume los riesgos de la actividad que autopractica, en la forma en que estime conveniente y apropiada, con los elementos y materia prima necesarios para su desempeño. ${ }^{11}$

9 GonZÁlEz, I., 2020: «Baja de turistas en Cuba demanda giro del sector», IPS Agencia de Noticias [en línea]. Disponible en: http://www.ipsnoticias.net/2020/02/baja-de-turistas-en-cuba-demanda-girodel-sector [Consulta: 18/03/2020].

10 Periódico Cubano, 2019: «Tras la suspensión de vuelos de EEUU a Cuba, Díaz-Canel dice: ‘Es el colmo de la impotencia» [en línea]. Disponible en: Periódico Cubano. https:/ / www.periodicocubano.com/ tras-la-suspension-de-vuelos-de-eeuu-a-cuba-diaz-canel-dice-es-el-colmo-de-la-impotencia/?utm_ source=Cubanos\&utm_campaign=1d9249170e-EMAIL_CAMPAIGN_2019_10_26_08_53\&utm_ medium=email\&utm_term=0_42dad8d593-1d9249170e-70473727 [Consulta: 13/02/2020].

11 EcuRed, 2019: «Trabajador por cuenta propia» [en línea]. Disponible en: Proyecto de Enciclopedia Colaborativa en Red del Gobierno de Cuba. https://www.ecured.cu/Trabajador_por_cuenta_propia [Con- 
Las disposiciones estatales para el impulso del TCP en Cuba se instituyeron a partir de 1993 mediante el Decreto-Ley No. 141 «Sobre el Ejercicio del Trabajo por Cuenta Propia». La Resolución Conjunta No. 1/1996 Reglamento del Ejercicio del Trabajo por Cuenta Propia identificó cuatro funciones sustantivitas de esta actividad, reconociéndola como un complemento al sector estatal de producción de bienes y servicios, una vía para incrementar los ingresos personales, un aporte al presupuesto estatal a través del cobro de tributos, así como una nueva alternativa de empleo.

Los antecedentes jurídicos mencionados devinieron en la promulgación de la Resolución No. 32/2010 del Ministerio de Trabajo y Seguridad Social en su función de organismo de autorización y control, ${ }^{12}$ la cual fue dictada al amparo del Decreto-Ley No. 141/1993; mediante ésta se ratificó el ejercicio del TCP a cargo del entonces Comité Estatal de Trabajo y Seguridad Social. Esta normativa fue derogada y puesta en vigor mediante la Resolución No. 33/2011;13 la misma contiene las disposiciones que regulan el ejercicio, ordenamiento y control de esta actividad. No obstante, estudios recientes detectan la existencia de «contradicciones en las regulaciones legales y económicas bajo las cuales se rige el desarrollo de la actividad de alojamiento turístico en el sector no estatal» (SILVEIRA et al., 2016: 71).

Desde esta conceptualización se reconoce que el Trabajador por Cuenta Propia o cuentapropista es «un empresario mercantil individual, pero que por una decisión del Estado (Administración Pública), se regula su actividad de forma diferente» (ANTúNEZ et al., 2013: 6). Este trabajador tiene el derecho de solicitar créditos privados y cooperativistas a través de los bancos estatales, pero solo está facultado para ofrecer servicios de alojamiento por concepto de hospedaje a turistas extranjeros, y los cobros/pagos debe realizarlos en moneda libremente convertible (CUC).

Como resultado de la institucionalización de esta actividad, se ha registrado un incremento importante de trabajos y trabajadores por cuenta propia. La cantidad de actividades autorizadas para el ejercicio del TCP en el año 2010 fue de 178, y en el año 2018 de 123, debido a ajustes introducidos. En tanto, la cantidad de cuentapropistas pasó de 157.351 en el año 2010 a 591.456 en 2018; para este último año, el 13\% de los trabajadores cubanos eran cuentapropistas y, de ellos, el $33 \%$ corresponde a mujeres y el $32 \%$ a jóvenes. ${ }^{14}$

A partir de la implementación de estas actividades privadas se han generado importantes contradicciones. E. SACCHETTI (2011: 41) reconoce que «la incertidumbre de los momentos iniciales y la desconfianza hacia un Gobierno que ya precedentemente (1968 y 1978) se había mostrado favorable al trabajo privado y luego lo había rechazado, indujo a muchos de estos pioneros a mantener una doble ocupación, en el sector público y en el privado». En la práctica, no

sulta: $13 / 02 / 2020]$.

12 Ministerio de Trabajo y Seguridad Social (MINTSS), 2010: «Resolución No. 32/2010», CUTC Cuba Sindical [en línea]. Disponible en: http://cubasindical.blogspot.com/2010/11/resolucion-no322010-ministerio-de.html [Consulta: 13/02/2020].

13 Ministerio de Justicia de la República de Cuba (MINJUS), 2011: «Resolución No. 33/2011», Gaceta Oficial No. 029 Extraordinaria de 7 de septiembre de 2011: 309 en línea]. Disponible en: https:/ / proyectoinventario.org/wp-content/uploads/GO_X_029_2011.pdf [Consulta: 13/02/2020].

14 Cubahora, 2018: «Trabajo por Cuenta Propia, preguntas y respuestas» [en línea]. Disponible en: Radio Rebelde. https://www.cubahora.cu/economia/trabajo-por-cuenta-propia-una-cronologia-depreguntas-y-respuestas [Consulta: 13/02/2020]. 
estaban creadas las condiciones para enfrentar «la diversificación de la estructura social cubana como efecto de la creación de espacios económicos múltiples, la redefinición de las identidades sociales a partir de nuevas culturas del trabajo emergentes y el cuestionamiento de algunos de los pilares ideológicos sobre los cuales se ha sustentado el modelo revolucionario, en particular en cuanto al trabajo» (SACCHETTI, 2011: 141).

El TCP en el ámbito del Turismo se institucionalizó mediante el Decreto-Ley No. 171/1997, lo que hizo posible reconocer legalmente el arrendamiento de casas como una actividad privada, ejercicio que ya con anterioridad se practicaba de manera informal. Este Decreto-Ley modificó el artículo 74 de la Ley No. 65/1988 de la Vivienda (Art. 1), y estableció que los propietarios de viviendas pueden arrendar, al amparo de lo establecido en la legislación civil común, viviendas, habitaciones con servicio sanitario propio o sin él, y otros espacios que se consideran parte integrante de una vivienda, mediante un precio libremente concertado, previa inscripción en la Dirección Municipal de la Vivienda (Art. 74).

En el ámbito de la gastronomía, la Resolución 4/1995 autorizó la apertura de pequeñas «fondas» (GAYNOSO, 2004) como vía para la generación del autoempleo. Mediante esta resolución se estableció la diferencia entre las «cafeterías», que sirven comida para llevar o consumir de pie en el local, un servicio que se ofrece en Pesos Cubanos (CUP), y los «paladares», cuyos clientes son extranjeros, a los que se permite su permanencia en el establecimiento, y que operan en Pesos Cubanos (CUP) o en USD y, desde 2004, en Pesos Cubanos Convertibles (CUP) (SACCHETTI, 2011; ANTúnez et al., 2013).

La legalización del sector turístico no estatal cubano introdujo nuevas perspectivas en el análisis económico y social, conformando un escenario en el que se incorporan conceptos hasta entonces incompatibles, como sector privado, Pequeña y Mediana Empresa (PYME), emprendimiento y competencia. Se afirma que «estos negocios no se consideran Pequeñas y Medianas Empresas de manera legislada, aunque presenten estas características» (SILVEIRA et al., 2016: 71), de igual forma se reconoce que los arrendadores «pueden considerarse emprendedores» y que "constituyen una competencia para las instalaciones turísticas estatales», además, se indica que «su mayor intención emprendedora no viene condicionada por sus variables sociodemográficas o culturales, sino por las percepciones de sí mismo como emprendedor y su profesionalidad» (SILVEIRA et al., 2016: 70).

Las actividades autorizadas para el Trabajo por Cuenta Propia (TCP) (2019) que tributan en el sector turístico se inscriben en las categorías de: arrendador de viviendas, habitaciones y espacios que son parte integrante de la vivienda; elaborador vendedor de alimentos y bebidas mediante servicio gastronómico (paladares), quienes ejercen la actividad en su domicilio mediante el uso de mesas, sillas banquetas o similares en hasta 20 capacidades; gestor de viajeros; trabajador contratado (solicitado por el TCP titular para laborar con él); transportador de carga y pasajeros; y figuras costumbristas como habaneras, cartománticas, vendedores de flores, etc. ${ }^{15}$

Como puede apreciarse, en el orden legislativo, de gestión, y científico técnico, se presenta un verdadero caos terminológico que no facilita la sistematización y registro de información, ya que se utilizan indistintamente conceptos tales como

15 Ministerio de Trabajo y Seguridad Social (MINTSS), 2019: Actividades autorizadas para el ejercicio del trabajo por cuenta propia [en línea]. Disponible en: http://www.cubaeduca.cu/media/www.cubaeduca.cu/ images/stories/cultura-economica/pdf/Actividades-autorizadas.pdf [Consulta: 13/02/2020]. 
TCP, cuentapropista, trabajo autónomo, autoempleo, empresa familiar, casa particular, casa privada de alquiler, hostal particular, entre otros. En términos comerciales, la «Casa Particular» es conocida como hostal particular (private house), similar a un B\&B (Bed and Breakfast), con desayuno generalmente incluido, en tanto que el «paladar» es reconocido como un restaurante privado (restaurant). Algunos de estos negocios utilizan sitios web especializados ${ }^{16}$ y la plataforma Airbnb para la publicidad y reserva de alojamiento a través de internet o de un dispositivo inteligente. ${ }^{17}$

Desde la perspectiva de los gestores de esta modalidad de alojamiento, el arrendamiento de habitaciones se identifica bajo el término «casa particular», concepto que fue introducido desde el año 1997, cuando se autorizó el alquiler para turistas en casas privadas. La renta puede darse en la tipología de habitación privada; habitación privada con entrada independiente (estudio o habitación tipo efficiency); apartamento, y villa o casa independiente. Esta actividad permite a la familia tener una mejor fuente de ingresos y enriquecer su cultura al interactuar con visitantes de diversos países.

Según el Equipo HospedajeCubano.com, las casas particulares ofrecen servicios de alojamiento económico a cargo del propietario y familia, así como otros servicios opcionales -desayunos, cenas, lavandería, guías de turistas, clases de baile y español, sitios web informativos, y reservas en línea. Tales negocios pueden operarse como ocupación principal o fuente secundaria de ingresos; cada casa se encuentra señalizada oficialmente con un logotipo en forma de ancla invertida que se reconoce en casi todas las láminas que ilustran este trabajo, y sus propietarios pagan un impuesto anual fijo por habitación. Las casas tienen ventajas sobre otros tipos de hospedajes, ya que propician mayor interacción con los cubanos, son más económicas que los hoteles, y los visitantes sienten que con su estancia contribuyen directamente al mejoramiento del nivel de vida de la familia cubana.

De esta forma, el desarrollo de empresas familiares turísticas se ha consolidado desde el año 2011 como estrategia para fortalecer la economía y continuar la transición hacia el nuevo modelo económico iniciado en torno al año 2009, por lo que la oferta de casas particulares sigue incrementándose (CANALES y SABARIEGOS, 2011; PÉREZ y NeL.LO, 2013). Éstas se distribuyen siguiendo patrones territoriales muy diversos y espontáneos -según posibilidades e intereses del propietarioy ocupan diferentes espacios en las ciudades, principalmente las de valores patrimoniales, conformando lo que CANALES y SABARIEGOS (2011) denominaron para la ciudad de Trinidad «un gran hotel disperso». Cabe destacar que en algunos destinos turísticos se ha considerado que la renta de casas particulares es una amenaza para el sector turístico estatal, por lo que se han establecido restricciones para este ejercicio.

El caso particular de la Ciudad de Cienfuegos no es diferente. Se comprobó que las casas privadas $u$ hostales (casa particular) corresponden a la modalidad de turismo no estatal o sector privado (TCP), y operan como Pymes; estas empresas familiares forman concentraciones geográficas asociadas a la zona patrimonial

16 Casa particular [en línea]. Disponible en: http://www.hospedajecubano.com [Consulta: 13/02/2020]; Casas Particulares Cuba [en línea]. Disponible en: https://www.casas-particularescuba.site [Consulta: 13/02/2020].

17 Airbnb [en línea]. Disponible en: https://www.airbnb.es/rooms/14942574?source_impression_id =p3_1583868960_7xg1V7X6B8mVRcRy [Consulta: 13/02/2020]. 
del centro de la ciudad, al Paseo del Prado, y a Punta Gorda. La infraestructura de alojamiento corresponde a varias habitaciones residenciales amuebladas, en un entorno familiar compartido que es propiedad de una familia, aunque en un pequeño número de habitaciones. A la vez, también pueden ofrecer al turista servicios de alimentos y bebidas, de internet y, en algunos casos, de transporte. Todo ello permite afirmar que esta oferta se basa en el concepto de multiproducto turístico, constituyéndose el propietario del alojamiento en un empresario mercantil individual, competitivo. Se localizan generalmente en edificios o viviendas de diferentes características tipológicas y se utiliza, en muchos casos, el propio valor patrimonial de la construcción, variando su fecha de edificación en dependencia del área geográfica en que se encuentran.

Las principales tendencias relativas a la composición de la demanda en la Ciudad de Cienfuegos coinciden con el comportamiento de estos indicadores a nivel nacional, tanto en términos de composición por sexo y formas de organización del viaje, como por motivaciones de viaje. Las preferencias hacia este tipo de establecimiento de alojamiento turístico también son coincidentes, integrándose en la regularidad que muestra el importante crecimiento de casas privadas de alquiler (hostales) en Cuba.

\section{LA CIUDAD DE CIENFUEGOS (CUBA) EN LA GEOGRAFÍA E HISTORIA LATINOAMERICANAS}

El estudio que se desarrolla está delimitado al espacio urbano patrimonial del municipio de Cienfuegos, capital de la provincia cubana homónima. Sin embargo, como marco de referencia, se ofrecen a continuación algunas de las características más significativas del conjunto del municipio. Su territorio tenía en 2015 (último dato disponible) una población de 174.769 habitantes, con una tasa de crecimiento anual de $0,54 \%,{ }^{18}$ por lo que es predominantemente urbana $(93,8 \%)$ y concentra en la capital el $43 \%$ de los residentes de la provincia.

Fue fundada por colonos franceses el 22 de abril de 1819 y es la única ciudad de América Latina que, durante la etapa de colonización española, presenta estas características. Su estratégica ubicación al centro-sur de la isla de Cuba y la presencia de una extensa bahía (aproximadamente $90 \mathrm{~km}^{2}$ ), favorecieron su vertiginoso desarrollo socioeconómico y un amplio intercambio comercial de ésta con otros puntos de la Tierra (Figura 1). Así, el desarrollo alcanzado fue de tal magnitud que, diez años después de su fundación, se le dio la categoría de villa y el nombre de Cienfuegos, en homenaje al Capitán General de la Isla. Luego, en 1880, alcanzó el título de ciudad de Cienfuegos.

En 1862 ya existían en su jurisdicción 85 ingenios azucareros (RoviRA y Olite, 1976), lo que denota la presencia de capitales y de población asociada a ellos que, vinculados a las plantaciones y a la producción de la caña de azúcar, permiten interpretar el intenso crecimiento poblacional y territorial de la ciudad en la segunda mitad del siglo XIX. El apogeo económico de estos años es también

18 Oficina Nacional de Estadísticas de la República de Cuba (ONE), 2016: Anuario Estadístico de Cuba 2010 [en línea]. Disponible en:. http://www.one.cu/aec2015/03\%20Poblacion.pdf [Consulta: 13/02/2020]. 
resultado de factores geográficos y técnicos. «La introducción del ferrocarril y la infraestructura de la época, creada en torno al puerto, impulsaron el crecimiento demográfico en la villa de Cienfuegos y sus espacios adyacentes» (RodRíGuez et al., 2018: 2). La evolución comercial, además, propició la llegada de profesionales de la construcción desde el extranjero, quienes tuvieron influencia positiva en la arquitectura de la ciudad. «Las primeras viviendas de mampostería se distinguen por la fachada de muro liso, sin aditamentos arquitectónicos, puerta al centro y ventanas de hierro a cada lado, de similar factura al tipo de "casa trinitaria 1830" " (GARCíA, 2019: s. p.), de las que sólo se conservan unas pocas. Se construyen, a continuación, las llamadas casas burguesas o casas coloniales, con amplios zaguanes y patios centrales, y las neoclásicas casas cienfuegueras, así como, posteriormente, la casa jardín. Todo ello contribuyó a que «en la segunda mitad del siglo XIX se consolide una tradición constructiva de alto empaque y color local, soporte del desarrollo arquitectónico posterior de la ciudad de Cienfuegos» (GARCíA, 2019: s. p.).

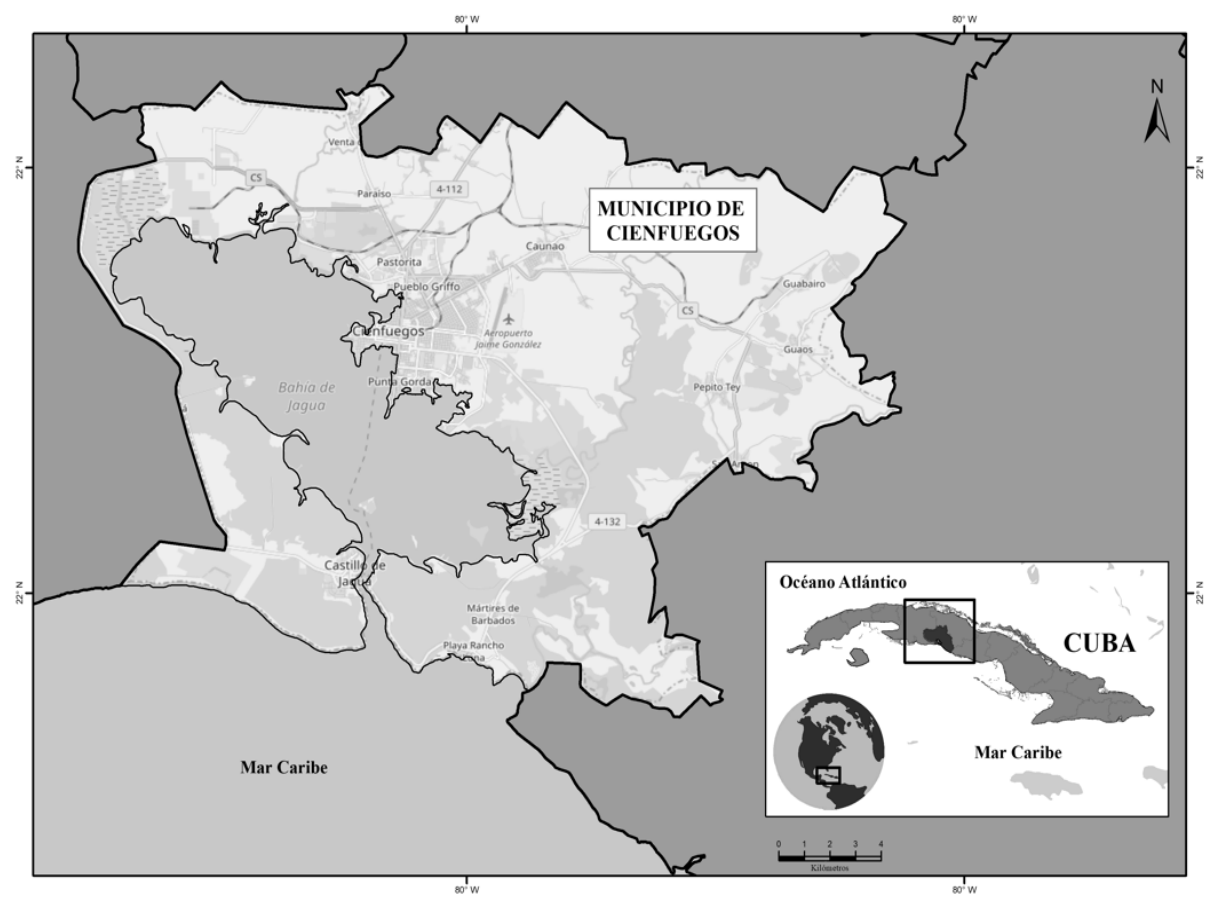

Figura 1. Localización geográfica del municipio de Cienfuegos, Cuba. Fuente: Autores.

A la par, los atractivos de esta urbe, amparados en inmuebles públicos de amplios portales, con proliferación de cúpulas y de arquitectura neoclásica, sus anchas aceras, y su trazado de norte a sur, que alcanza la armonía perfecta de las líneas rectas, propiciaron que fuera bautizada como la Perla del Sur, denominación 
popular que aún conserva. Al respecto de los logros arquitectónicos de la ciudad, I. MiLLÁN señala:

Ya La Habana existía y se conocía, y Santiago, y la preciosa Trinidad, pero nosotros tuvimos la suerte de que los que llegaron aquí [Cienfuegos] trajeron lo mejor de su cultura e hicieron una ciudad para disfrutarla. En Cienfuegos el mérito fundamental es el espacio público, que se convierte en escenario de una vida social que palpita a través de sus elegantes calles, paseos y alamedas. ${ }^{19}$

La primera manzana del poblado, que fue reservada para la Plaza de Armas (hoy Parque José Martí), fue el referente para los primeros trazados, «lo que determinó la concentración urbana alrededor de este centro inicial de la ciudad, lugar en el que se localiza actualmente la mayor parte de los servicios» (FABREGAT, 2014: 69). Esta Plaza tiene el doble de tamaño que cualquier otra Plaza de Armas de Cuba y es la única en el país que cuenta con un Arco de Triunfo (Lámina 1). Destaca, además, por su magnitud e importancia, el Paseo del Prado (el mayor de Cuba), de casi dos kilómetros de longitud, que actúa como columna vertebral del territorio, repartiendo la ciudad a ambos lados.

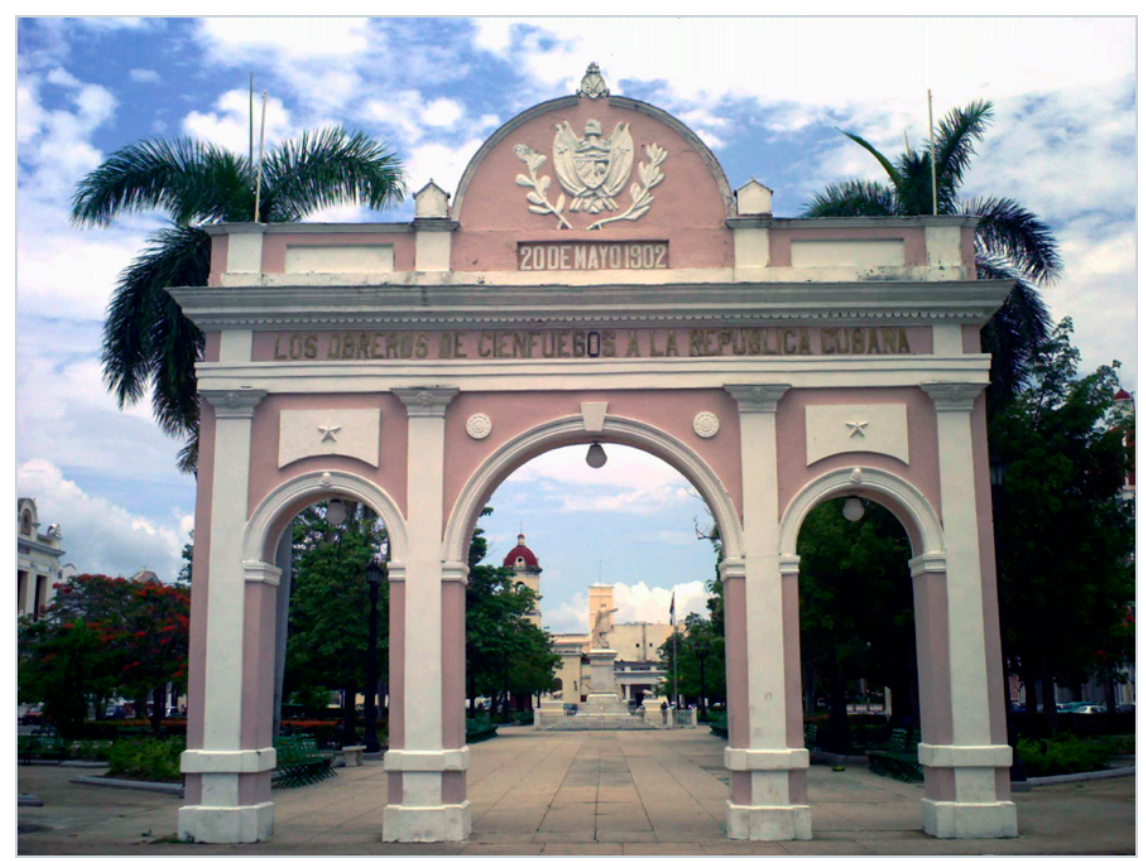

Lámina 1. Arco de Triunfo en el Parque Martí, Cienfuegos.

Fuente: Autores.

19 Millán, I., 2018: «Cienfuegos y Camagüey, dos sorpresas muy cubanas» [en línea]. Disponible en: El País [en línea], https://elviajero.elpais.com/elviajero/2018/02/22/actualidad/1519298794_634997. html [Consulta: 13/02/2020]. 
En el año 1995, el centro histórico urbano de Cienfuegos fue declarado Monumento Nacional; diez años después se declararon Patrimonio Cultural de la Humanidad setenta hectáreas (setenta manzanas) y 1.521 inmuebles de dicho centro histórico, por lo que se convirtió en la única ciudad de América Latina fundada en el siglo xIX que tiene ese reconocimiento de la UNESCO. ${ }^{20}$ Para ello, se tuvo en cuenta, entre los aspectos de mayor peso, que la ciudad es el primer y más notable ejemplo de conjunto arquitectónico y urbanístico en el que se plasmaron las nuevas ideas de modernidad, higiene y urbanismo surgidas en América Latina en el siglo XIX.

Este galardón está considerado el hecho cultural más relevante logrado por Cienfuegos, debido a su proyección y alcance, toda vez que los valores reconocidos dejan de constituir patrimonio exclusivo de los habitantes de esta urbe para trascender fronteras. Así, su belleza y majestuosidad convierten a la ciudad y a su centro histórico en un bien patrimonial sobresaliente, por sus características urbanísticas, arquitectónicas, paisajísticas, ambientales, naturales y comerciales, tanto a nivel nacional como internacional. Se trata de una de las ocho regiones prioritarias para el desarrollo turístico de Cuba.

El sistema de turismo en el municipio de Cienfuegos está integrado por una planta hotelera estatal con 861 habitaciones en once instalaciones y 1.497 habitaciones del sector no estatal, distribuidas en 703 casas $^{21}$ aunque, en la actualidad, alcanzan casi las 1.000 (2019). Entre los hoteles de mayor confort están Rancho Luna, Faro Luna, La Unión y Palacio Azul operados por el Grupo Cubanacán; el Hotel Jagua y Casa Verde del Grupo Gran Caribe, y la Villa Guajimico del Grupo Campismo Popular. Cuatro de ellos se localizan en la ciudad y el resto en espacios litorales y de naturaleza (GutiérRez, 2011). ${ }^{22}$ Complementan el producto turístico la náutica, destacando Marina Marlín, con categoría de puerto internacional. El destino tiene, además, un aeropuerto internacional a tres $\mathrm{Km}$. de la ciudad, puntos de rentas de autos y motos, restaurantes especializados, centros nocturnos, tiendas turísticas y agencias de viajes con contratos con los hostales particulares, los paladares y el transporte.

Los principales mercados turísticos de la ciudad han sido Alemania, Canadá, Reino Unido, Francia, España, Suiza y Holanda, así como el mercado italiano, que prefiere los hostales particulares. ${ }^{23}$ En términos de llegadas Cienfuegos recibía 72.189 turistas internacionales en el año 2009, esta cifra se incrementó considerablemente y el volumen de visitantes extranjeros al cierre del 2015 fue de 171.346. ${ }^{23}$ Sin embargo, esta tendencia cambió en 2019, pues disminuyó la llegada de turistas respecto al año anterior (de canadienses, europeos y estadounidenses)

20 Batista Díaz, S., 2015: «Declaratoria del Centro Histórico Urbano de Cienfuegos como Patrimonio Cultural de la Humanidad» [en línea]. Disponible en: El Blog de Cienfuegos Patrimonio. https:/ / cienfuegospatrimonio.wordpress.com/patrimonio-cultural/declaratoria [Consulta: 18/03/2020].

21 BARCiA, I., 2017: «Los nuevos derroteros del turismo en Cienfuegos», 5 de septiembre, Diario Digital de Cienfuegos [en línea]. Disponible en: http:/ / www.5septiembre.cu/los-nuevos-derroteros-del-turismoen-cienfuegos [Consulta: 18/03/2020].

22 GutiérRez, F., 2011: «Análisis de Cienfuegos, Cuba, como destino turístico», Gestiopolis [en línea]. Disponible en: https://www.gestiopolis.com/analisis-de-cienfuegos-cuba-como-destino-turistico [Consulta: 18/03/2020].

23 MARTínEZ, J., 2016: «Crece arribo de turistas a Cienfuegos», Granma [en línea]. Disponible en: http:/ / www.granma.cu/cuba/2016-11-11/crece-arribo-de-turistas-a-cienfuegos-11-11-2016-23-11-17 [Consulta: $18 / 03 / 2020]$. 
y se redujo el arribo de cruceros, a pesar de lo cual fueron recaudados más de 94 millones de CUC (PÉrEZ, 2020).

Uno de los factores que ha contribuido al mejor posicionamiento estratégico del turismo en Cienfuegos está relacionado con la conservación y rehabilitación del patrimonio cultural de su centro histórico. Para ello se constituyó la Oficina del Conservador de la Ciudad, que tiene entre sus propósitos la preservación de la memoria histórico-cultural (material e inmaterial) mediante la restauración de sus valores históricos, constructivos, ambientales y sociales. ${ }^{24}$ En consecuencia, varios inmuebles del sector estatal se han beneficiado de estos proyectos de rehabilitación de inmuebles y de sus espacios exteriores. Entre estos destacan los del Palacio de Blanco, la restauración de los portales del Paseo del Prado, la reparación de la Casa de los Leones y la rehabilitación del Cementerio de Reina, entre otros. ${ }^{25}$

Por otra parte, la planta alojativa del sector no estatal, que fortalece el sistema turístico de la ciudad también se ha visto beneficiada. Las encuestas realizadas, han desvelado que estos inmuebles cienfuegueros (hostales) comenzaron su explotación turística a partir de los años 1997-1998, ${ }^{26}$ aunque hasta el año 2000 solamente un quinto de ellos ofrecía sus servicios. Sin embargo, entre el año 2010 y 2017, resurgió el negocio, obteniendo el permiso para el desarrollo de la actividad turística el 50\% de los actuales hostales. Estos inmuebles, además de ofrecer alojamiento, en un $88,7 \%$ brindan otros servicios, como desayunos $(86 \%)$, internet $(61 \%)$ y transporte $(32,7 \%)$.

\section{ANÁLISIS GEOGRÁFICO Y PATRIMONIAL DE LAS INTERVENCIONES TURÍSTICAS PRIVADAS EN LA CIUDAD DE CIENFUEGOS}

\subsection{La localización}

Como puede apreciarse en la Figura 2, una parte de los numerosos hostales (casas particulares, en su mayor parte) que conforman la oferta turística de la ciudad se localiza en las proximidades de la Plaza José Martí, antigua Plaza de Armas, es decir, en la trama del primer desarrollo urbano, en el centro histórico de la ciudad, compuesto por 25 manzanas estrictamente parceladas en estructura de retícula ortogonal regular, en forma de tablero de ajedrez (FERRER, 2018), las cuales circundan una primera parcela de 100 varas castellanas de lado (Plaza de Armas), y ordenan este trazado en cuadrícula perfecto, delimitado por las calles de Santa Elena (avenida 60), al Norte; Santa Clara (avenida 50), al Sur; Velazco

24 CONSERCF, 2018: «Oficina del Conservador de la Ciudad de Cienfuegos» OCCCF [en línea]. Disponible en: http://occcf.cienfuegos.cu [Consulta: 18/03/2020].

25 BATISTA, S., 2013: «Restauran inmuebles patrimoniales de Cienfuegos», El Blog de Cienfuegos Patrimonio. [en línea]. Disponible en: https://cienfuegospatrimonio.wordpress.com/2013/05/31/restauraninmuebles-patrimoniales-de-cienfuegos [Consulta: 18/03/2020].

$26 \mathrm{El}$ año de apertura de los primeros establecimientos se relaciona con el cambio de normativa del país: Decreto Ley No. 171 con fecha del 15 de mayo de 1997 y modificado por el Decreto Ley No. 275 con fecha del 30 de septiembre del 2010, ambos documentos «Sobre el arrendamiento de viviendas, habitaciones o espacios». 
(calle 23) al oeste y Hourritiner (calle 33) al este (RoDRíGuEz, 2014) (Figura 2, zona $1)$.

Otro importante número de alojamientos turísticos se halla en el área de la primera expansión urbana, en distintas manzanas de la estructura reticular que caracterizó el proceso de urbanización hacia el este, a consecuencia de la llamada reconcentración decretada por el Capitán General Valeriano Weyler, en 1896 (concentración de la población rural en núcleos urbanos, para prevenir los conatos independentistas que fueron desgastando al ejército español hasta el fin de la guerra en 1898) (STUCKI, 2017) (Figura 2, zona 2). También cuenta con un considerable número de inmuebles dedicados al alojamiento turístico el Paseo del Prado (actual calle 37). Se trata de una arteria vertebral de la estructura urbana, que actúa como elemento distribuidor del tránsito vial y peatonal que enlaza el norte y el sur de la ciudad (Figura 2, zona 3).

Finalmente, el antiguo reparto Ruiloba, actual Punta Gorda, que comenzó su urbanización en 1927 a partir de un eje principal, el Paseo Aragonés (prolongación de la Avenida de la Independencia, antigua denominación del Paseo del Prado), cuenta también con algunos hostales, aunque su número es menor, dado que muchos de sus propietarios han conservado los inmuebles para un uso privado, debido a que este espacio fue ocupado por familias de alto nivel adquisitivo, huella que se ha preservado, a pesar del proceso revolucionario (Figura 2, zona 4).

\subsection{El valor patrimonial}

La relación entre el patrimonio cultural de la ciudad de Cienfuegos y el turismo se ha materializado mediante un proceso de planificación de Puesta en Valor Turístico (PVT), que tiene sus antecedentes en la legislación cubana de la década de los años noventa del siglo xx y que se refleja en el sistema turístico de Cienfuegos. El proceso de PVT del patrimonio material e inmaterial en la nueva era del turismo internacional de esta ciudad se ha basado en la revalorización de los recursos y atractivos históricos patrimoniales, concentrados en su zona centro, y en la remodelación y/o ampliación de la planta turística asociada a los atractivos urbanos y lugares de interés histórico cultural.

Así, por ejemplo, entre 2011 y 2015 se desarrolló un importante proceso inversionista en el sector turístico, siendo inaugurados los Hoteles Encanto Casa Verde y Perla del Mar y remodelado el Hotel San Carlos, perteneciente al complejo Meliá-Jagua. Todos ellos ocupan inmuebles valiosos que han sido restaurados para su uso turístico y que de otra manera habrían perdido su atractivo. Tales vínculos entre el patrimonio y el turismo ponen de manifiesto un proceso de doble relación de impactos ya que, por una parte, el turismo ha contribuido a la rehabilitación y conservación del patrimonio cultural de la ciudad, a la vez que el rescate del patrimonio ha potenciado el desarrollo y consolidación del turismo cultural en este destino urbano, constituyéndose en un binomio que fortalece múltiples encadenamientos funcionales.

No obstante, en lo que respecta a este estudio, analizamos una actividad turística privada, cuya regulación, como ya hemos señalado, se hizo necesaria para encontrar alivio a una situación de profunda crisis económica. Por tanto, la conservación patrimonial que descansa en estas pequeñas acciones no 
deriva directamente de iniciativas públicas, aunque se beneficia de los planes de rehabilitación de forma indirecta, pues se trata de la inversión que afrontan pequeños emprendedores para garantizar el atractivo turístico de sus inmuebles, con la finalidad fundamental de incrementar o garantizar sus ingresos.

De acuerdo con la información que nos proporcionaron las encuestas realizadas (Tabla 1), la mayor parte de los hostales que se sitúan en el Centro histórico y en Punta Gorda (reparto residencial) fueron construidos en el periodo prerrevolucionario (72\%), predominando en ellos el estilo arquitectónico colonial y neoclásico $(65,3 \%)$ y comenzaron a desarrollar la actividad turística antes que el resto de las viviendas encuestadas, lo que demuestra su mayor atractivo turístico, íntimamente relacionado con su valor patrimonial y su posición central en la trama urbana.

En consonancia con esta localización geográfica, los hostales presentan ciertas características formales que se corresponden con los estilos arquitectónicos propios de las distintas fases de urbanización. Así, en las zonas 1 y 2 de la Figura 2, la conformación de las manzanas en solares rectangulares, en trama compacta en orden cerrado, con edificaciones contiguas, y separadas mediante paredes medianeras, favorece la prolongación de paramentos y, por tanto, las fachadas continuas. En ellas se exhiben elementos del neoclasicismo, propios de la tipología constructiva que se desarrolló en dicha ciudad desde principios del siglo XIX hasta las primeras décadas del siglo xx.

Cabe recordar que se ha identificado el orden, la simetría y el canon de Cienfuegos con la influencia francesa que derivó del hecho de que la ciudad fuera fundada en 1819 con colonos blancos de ascendencia francesa, bajo el dominio de la Corona Española (BRITO, 2010). Por tanto, los elementos propios del neoclasicismo, que tanto éxito cosechaban unos años antes en Europa y, especialmente, en Francia y España, se ofrecen mediante un orden riguroso en las fachadas, con puertas enmarcadas por pilastras, molduras, guardapolvos, jambas y cornisas rematadas por pretiles, así como por vanos con lucetas y medios puntos de cristalería. A estos elementos formales, desde las últimas décadas del siglo XIX, se añaden los trabajos en hierro forjado o fundido, especialmente en rejas, lo que denota la influencia que adquiere la nueva arquitectura del hierro que, en Cienfuegos, se desarrolla tan sólo como un útil complemento decorativo y no como elemento constructivo.

En las fachadas de los hostales de la Lámina 2, correspondientes con las primeras fases de urbanización de la ciudad, es posible reconocer la contigüidad de paramentos, la utilización de molduras que refuerzan el orden y la simetría, las cornisas denticuladas, las pilastras encastradas, los pretiles abalaustrados, los vanos abovedados con lucetas, en arcos de medio punto, y las ménsulas y capiteles como elementos decorativos. A ellos se suman, como ya se había señalado, trabajos de una elaborada rejería en puertas y ventanas. 
Patrimonio urbano y alojamientos turísticos en Cienfuegos (Cuba)

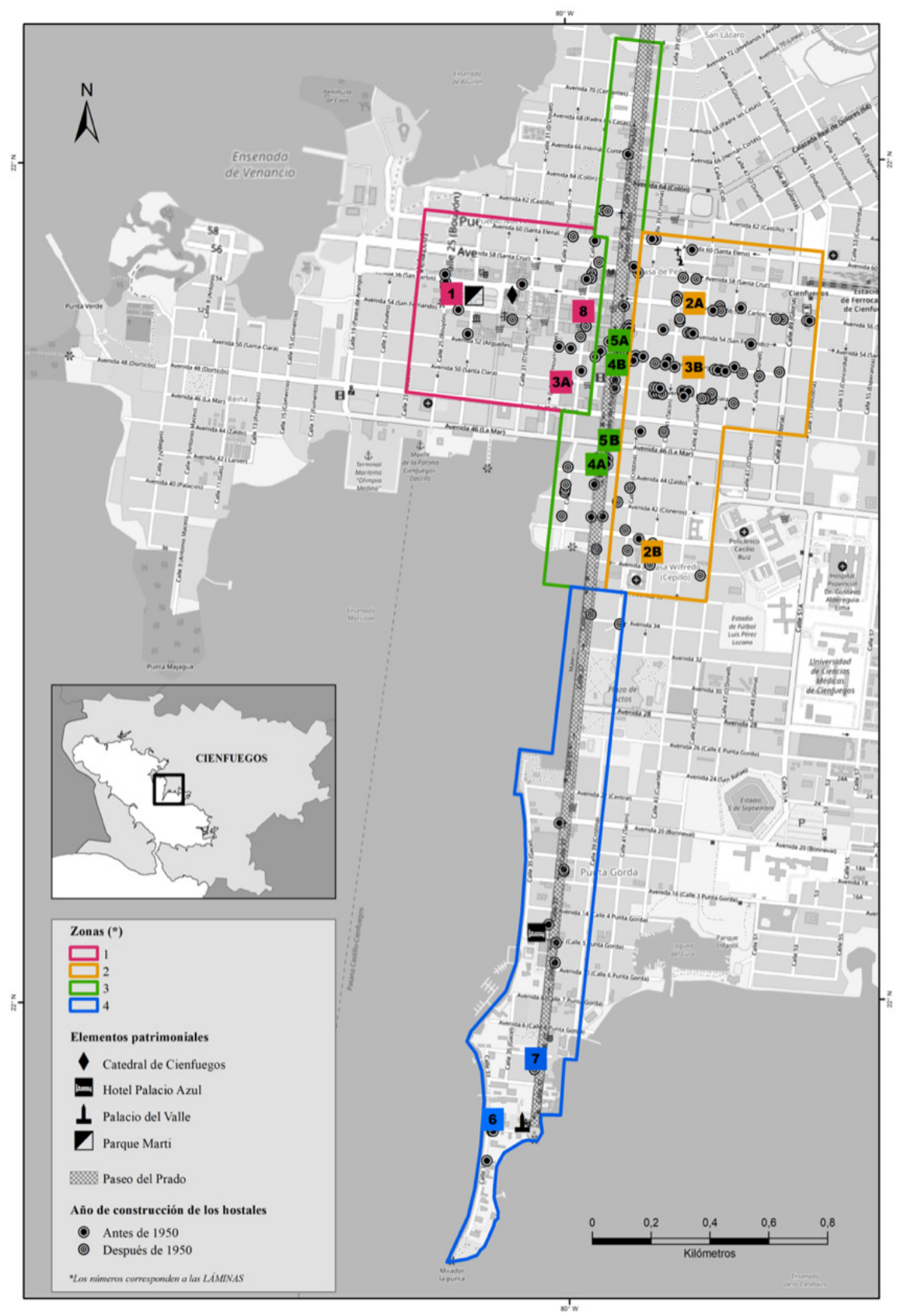

Figura 2. Localización de los elementos y zonas patrimoniales de Cienfuegos Fuente: Autores. 

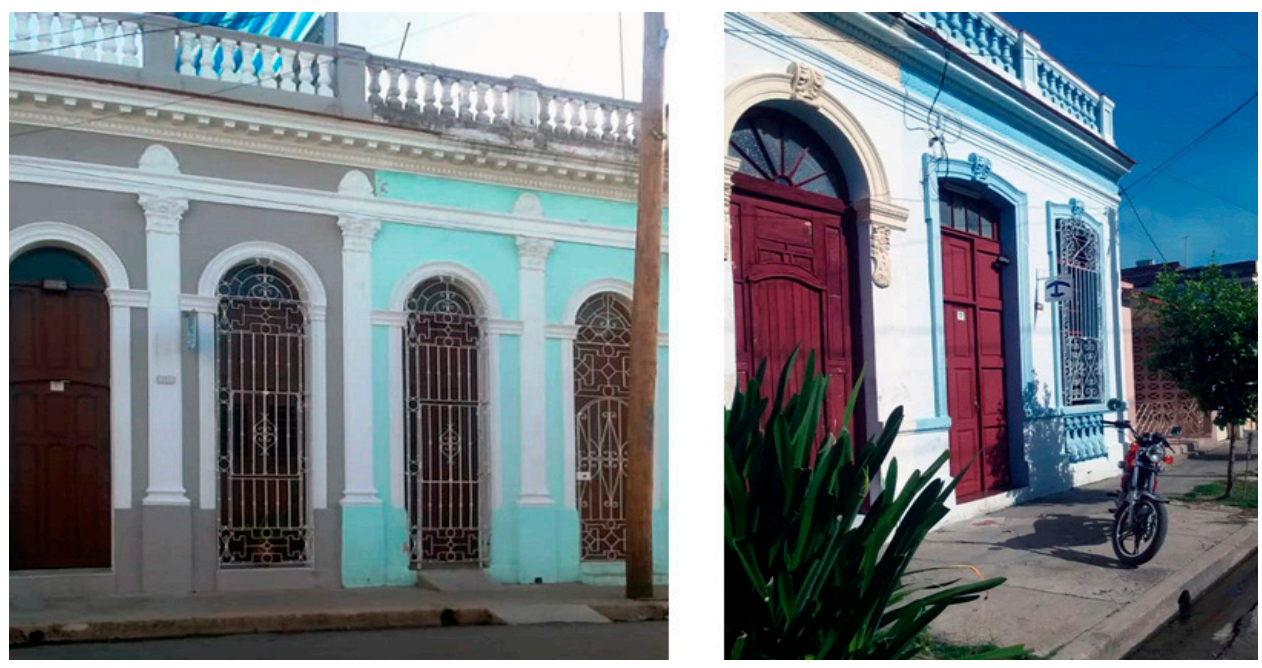

Lámina 2. Izquierda (2A) Hostal en Avenida 56 nº 4115 y derecha (2B) Hostal en Calle $41 \mathrm{n}^{\circ}$ 3817. Fotografías: Autores.

Al estilo neoclásico le suceden, sin solución de continuidad, en la misma zona caracterizada (zona 1 y 2 de la Figura 2), las edificaciones que ensayan un mayor ornato, con elementos que combinan neoclasicismo y eclecticismo. Los estilos recurrentes, de fines del siglo XIX, ofrecen nuevos códigos formales, que renuevan las fachadas, produciéndose una más compleja integración de estas tendencias en el conjunto heredado. Así, como puede apreciarse en la Lámina 3, se da una mayor profusión de elementos decorativos: frisos con grecas y guirnaldas, ménsulas que enmarcan los vanos, etc., al mismo tiempo que algunos inmuebles comienzan a renovarse ganando altura, con una segunda planta.
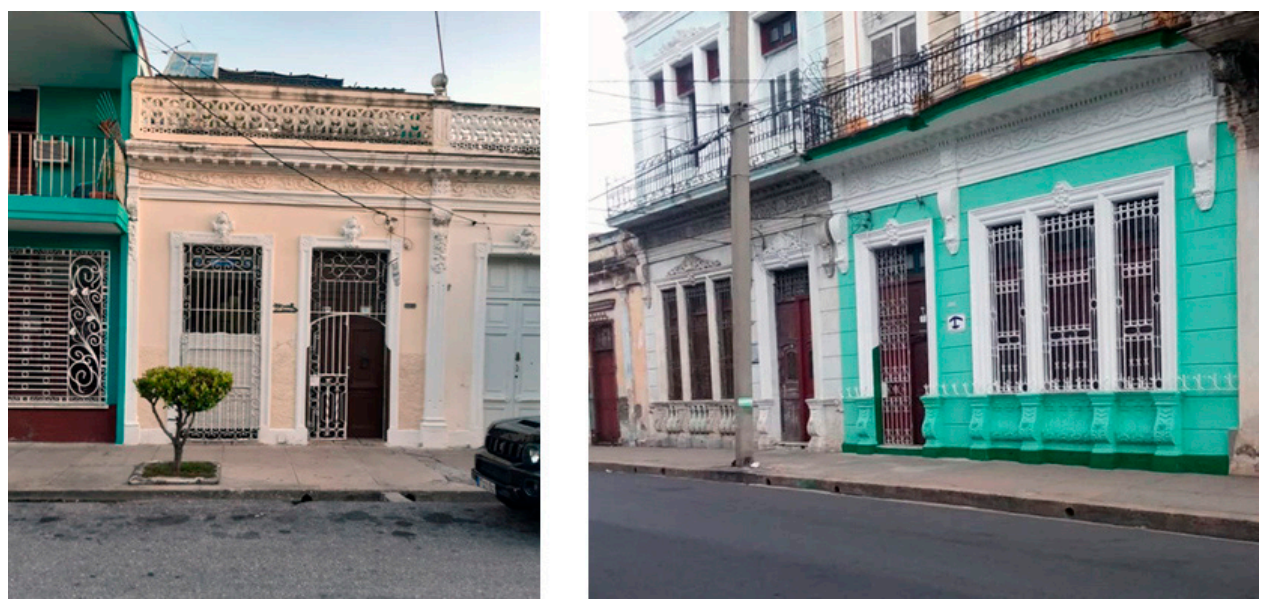

Lámina 3. Izquierda (3A) Hostal Cienfuegos Center y derecha (3B) Hostal en Avenida 52 e/ 41 y 43. Fotografías: Autores. 
La tercera zona a la que se ha aludido, y que articula el Paseo del Prado (zona 3 de la Figura 2), como auténtica columna vertebral, ofrece una modalidad arquitectónica propia, la de inmuebles porticados que, al sucederse, originan toda una galería techada, una circunstancia que favorecía el paseo y el intercambio social, pues se trata del barrio burgués, por excelencia, el de la primera mitad del siglo xx y el más cualificado ambientalmente.

La tipología arquitectónica de esta zona se vale de los mismos códigos estéticos que se han caracterizado anteriormente, aunque los elementos decorativos ganan una mayor riqueza, y las columnatas que anteceden al cuerpo de los inmuebles se convierten en las estructuras más representativas. Como puede apreciarse en las Láminas 4 y 5, se emplean columnas de orden jónico (Lámina 4) o corintio (Lámina 5), sobre plataformas, cuyos fustes acanalados se levantan sobre basas y se rematan con capiteles de volutas, en el primer caso, o con capiteles de hojas de acanto, en el segundo, dando paso a un arquitrabe, a un friso profusamente decorado con guirnaldas y a una cornisa, de la que penden ménsulas, y que remata un segundo cuerpo, adelantado respecto al primero, cuando se trata de construcciones de dos plantas (Lámina 4). En esta segunda planta se siguen ensayando los motivos decorativos y se continúan empleando las columnas, ya sea flanqueando los vanos, o como parteluz. Y cuando el inmueble es de una sola planta, sobre la cornisa descansa el paramento de la techumbre plana de la cubierta (Lámina 5).
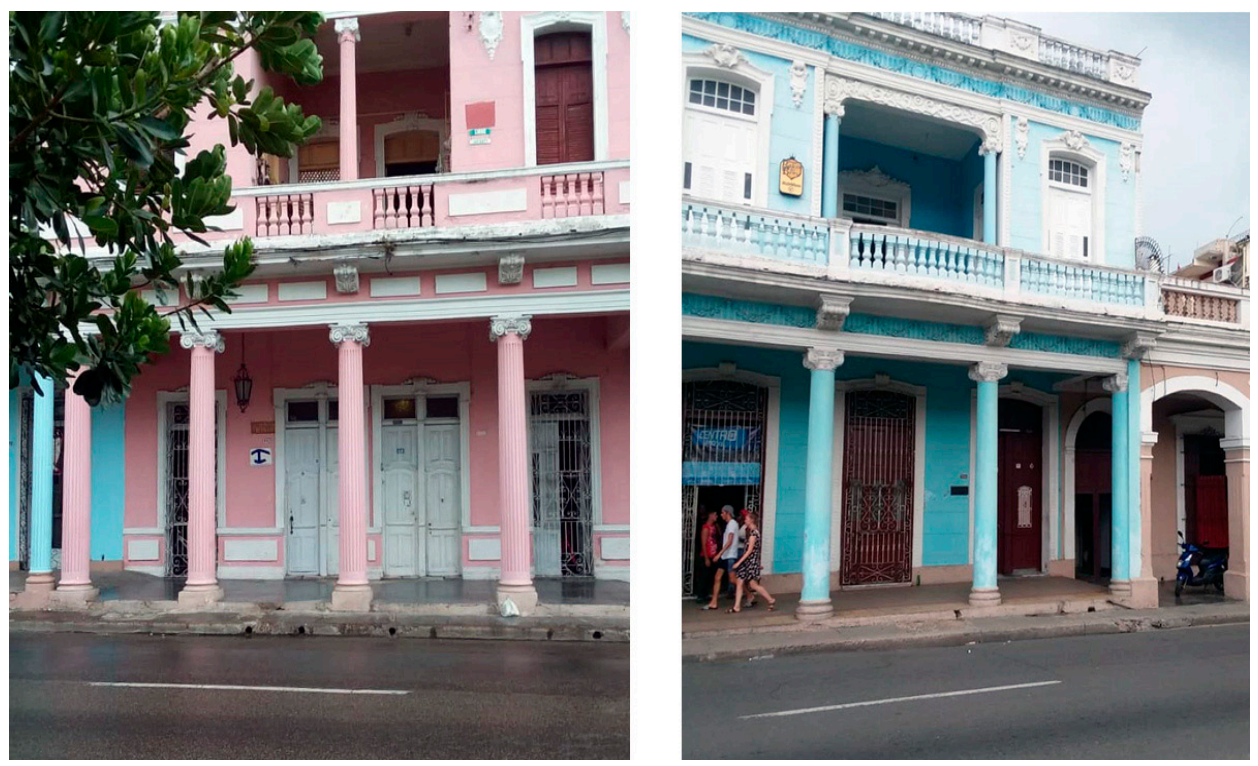

Lámina 4. Izquierda (4A) Hostal Doña Amalia y derecha (4B)

Hostal Dr. Mantecón en el Prado. Fotografías: Autores. 

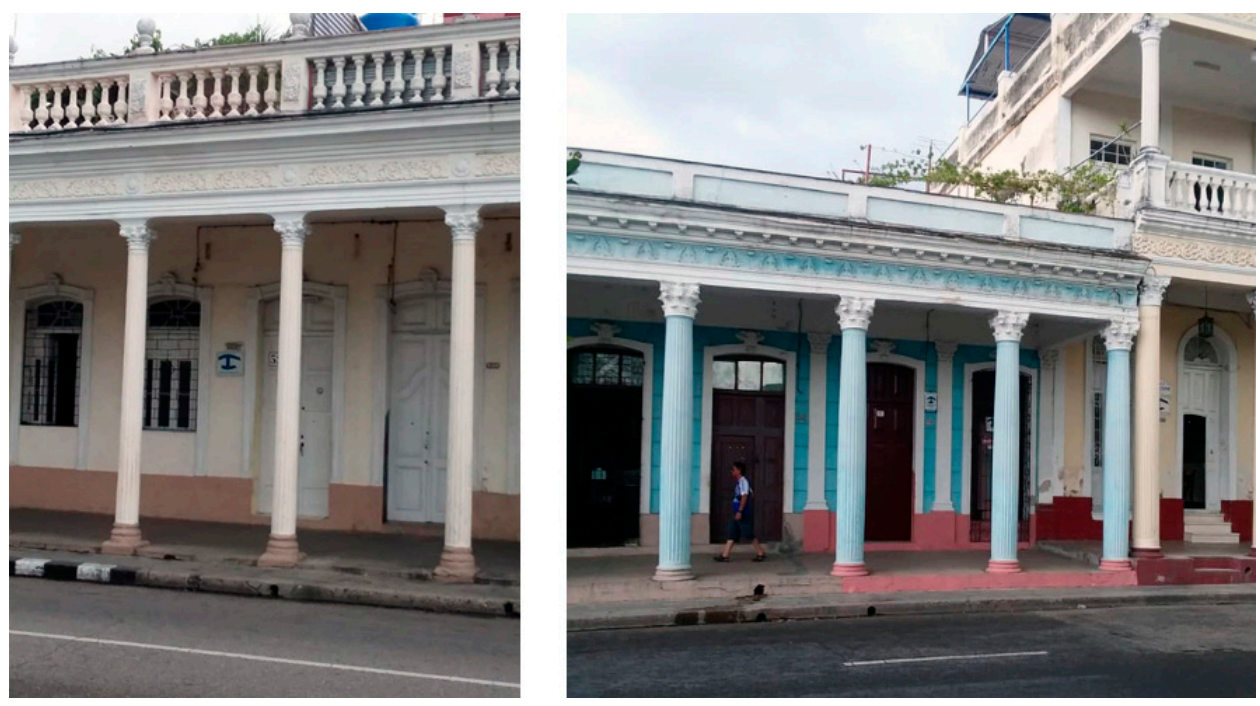

Lámina 5. Izquierda (5A) Hostal en el Paseo Prado no 5212 y derecha (5B) Hostal en el Paseo del Prado $n^{\circ}$ 4422. Fotografías: Autores.

En cuanto a la zona de Punta Gorda, tan sólo se hallan unos pocos inmuebles de los dedicados a la actividad turística (zona 4 de la Figura 2). Se trata de edificios que obedecen a una tipología completamente distinta, y cuya antigüedad es mucho menor, dado que fueron construidos en la década de los años cincuenta del siglo xx. En su mayoría, son un exponente de vivienda de tipo chalet, bungaló o quinta, en la que se usa la madera y la mampostería y que se hallan en zonas destinadas al descanso y recreo. Es posible que haya que vincular este tipo de inmuebles a la influencia norteamericana (FERRER, 2018), si bien, algunos autores se refieren a algunas de ellas como obra del arquitecto Federico Navarro Taillacq (1885-1964), quien recurrió al arco en el portal y a la cubierta inclinada de tejas francesas en una de las documentadas en esta zona como de su autoría (CABALLERO, 2016).
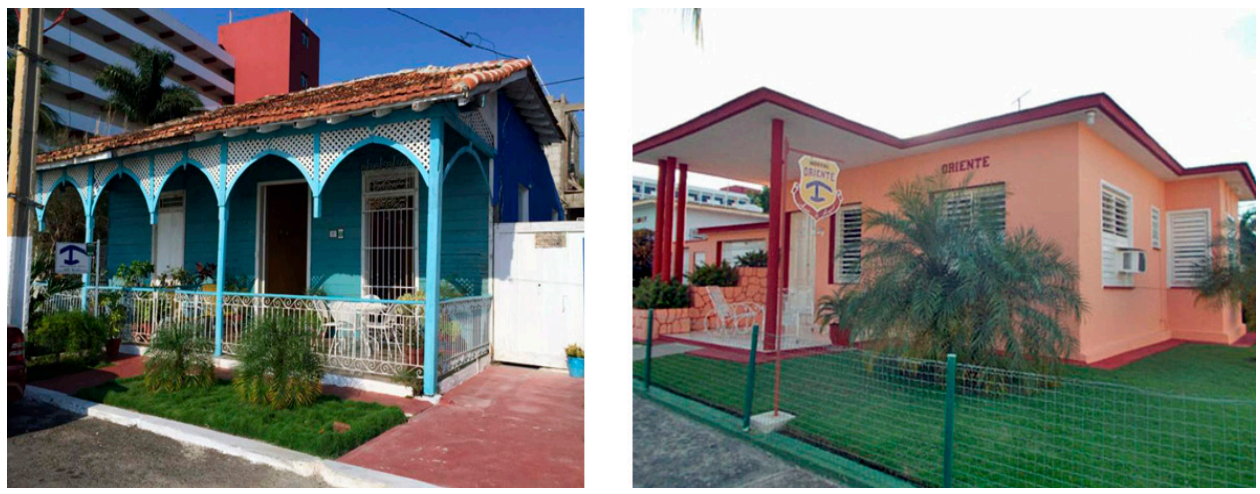

Lámina 6. Izquierda (6A) Hostal Sol Bahía, Punta Gorda y derecha (6B) Hostal Oriente, Punta Gorda. Fotografías: Autores. 
La lámina 6 ilustra esta tipología. El Hostal Sol Bahía (Lámina 6, izqda.) combina como materiales constructivos la mampostería, las tejas de la techumbre ligeramente inclinada y el voladizo que cubre un porche de madera. Lo más significativo de este último son los arcos ligeramente apuntados, sostenidos por columnas y pinjantes (arcos suspendidos sin apoyo de columnas) alternos. También resulta interesante la solución en celosía de los paños del alfiz.

La fecha de construcción de este inmueble, según la información proporcionada por su propietario, es la de 1930, por tanto, una de las quintas de recreo más antiguas de Punta Gorda. En cuanto al Hostal Oriente (Lámina 6, dcha.), la factura del inmueble es completamente distinta y denota su menor antigüedad; su fecha de construcción es probablemente de fines de los años 50 . En él predominan las formas racionalistas, o también llamadas del estilo moderno o internacional, que tanto éxito adquirieron en Europa y Estados Unidos en los años treinta, cuarenta y cincuenta del siglo xx y que defendían, como código estético, las líneas sencillas y funcionales, basadas en formas geométricas simples, renunciando a la ornamentación. No cabe duda de la influencia que pudo ejercer el movimiento internacional norteamericano en el diseño de esta vivienda de recreo, reconvertida hoy en hostal.

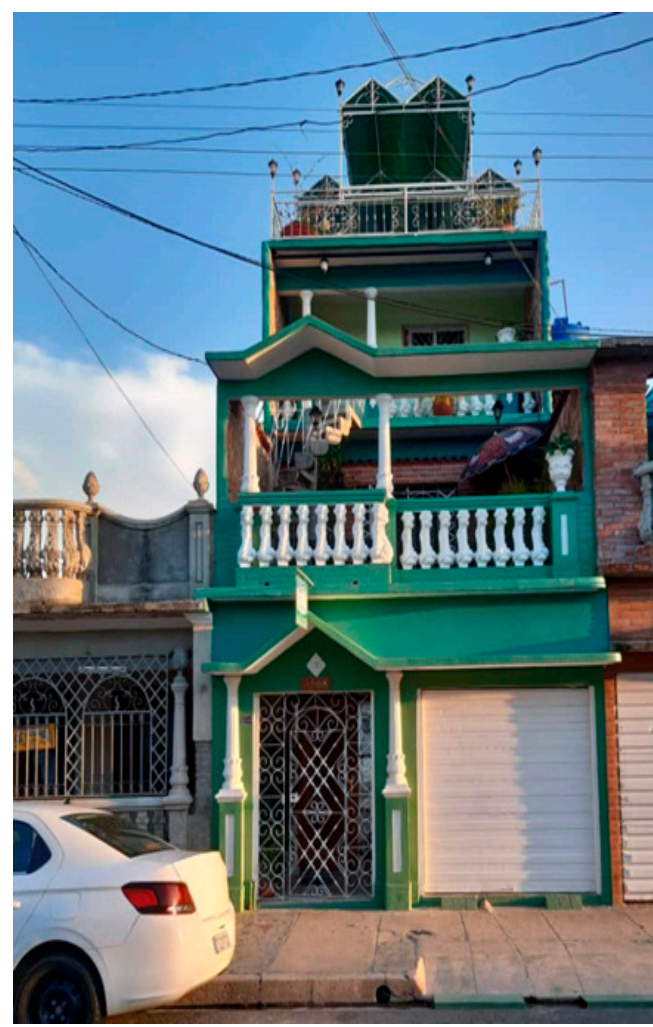

Lámina 7. Hostal León, Calle 35 n ${ }^{\circ}$ 5407. Fotografía: Autores 
Cabe mencionar que estos inmuebles conviven con otros propios del periodo revolucionario, como sucede en gran parte de las ciudades coloniales cubanas. Esta heterogeneidad está justificada, entre otros factores, por las reconstrucciones totales de varios inmuebles debido a su destrucción por el paso de los años o por la afectación de huracanes. También se realizan obras nuevas allí donde hay espacios que así lo permiten, en solares libres, como sucede en la zona de Punta Gorda, o en otros sectores consolidados, donde la necesidad de vivienda lleva a la división y al crecimiento vertical del inmueble (Lámina 7).

Por otra parte, es necesario apuntar que el estilo singular que se corresponde con los años revolucionarios (después del 1959 hasta la actualidad) no tiene una nomenclatura bien diferenciada en la literatura, y tampoco elementos que apunten a una estética particular, según la información proporcionada telefónicamente por arquitecto cubano, residente en Madrid, Fernández Hernández (2019). Son viviendas de autoconstrucción cuyo estilo está marcado por la disponibilidad de recursos del propietario. En consecuencia, en el centro urbano, el Paseo del Prado y Punta Gorda, se reconoce una cierta heterogeneidad, pues se combina en ellos una mezcla de estilos del pasado pre-revolucionario y del periodo revolucionario.

Por último, es necesario hacer mención a un hecho ajeno a la descripción formal de los inmuebles, pero que puede apreciarse en las distintas imágenes seleccionadas, el del buen estado de conservación que ofrecen las construcciones que se utilizan como alojamientos turísticos con respecto a otras de uso privado, una circunstancia que valida la hipótesis inicial de este trabajo, la de la capacidad de la inversión privada en la promoción turística como factor que contribuye a la conservación y revalorización del patrimonio arquitectónico de la ciudad de Cienfuegos.

\section{CONCLUSIONES}

La investigación pone de manifiesto que el turismo es una de las actividades que mejor contribuye a visualizar la dimensión económica del patrimonio urbano y a despertar preocupación por su conservación. En tal sentido, se constata que la cultura y los bienes culturales patrimoniales de Cienfuegos han contribuido al desarrollo económico y social local mediante su uso turístico, por lo que la PVT de los bienes culturales puede generar riqueza y empleo durante las diferentes etapas en que los bienes y servicios culturales se producen, distribuyen e intercambian. En función de ello el turismo incorpora los valores estéticos, históricos, sociales, simbólicos, y económicos de uso directo (turístico recreativos) y de no uso que existen en la ciudad, todo lo cual permitirá la reproducción y renovación constante de la cultura, así como la calidad de vida de la comunidad anfitriona. Se hace oportuno destacar que en el caso de Cienfuegos no se advierten los riesgos denunciados por algunos especialistas con relación a los perjuicios del overtourism en destinos urbanos patrimoniales, pues la afluencia de visitantes no supera la capacidad de carga de la infraestructura o de los bienes que se ofrecen para el disfrute de los visitantes.

Las razones que determinan la importancia de la actividad turística para la conservación del patrimonio urbano de Cienfuegos descansan en factores de muy diverso tipo. Por una parte, en factores de carácter económico, dado que 
este tipo de turismo se ha convertido en un recurso fundamental no sólo para el Estado, sino también para la comunidad local y para las familias. Muchas de ellas acogen a los turistas, en su propia vivienda, en determinadas habitaciones destinadas a tal fin, tras haberse convertido algunos de sus miembros en pequeños emprendedores de un tipo de negocio reconocido como trabajo por cuenta propia en la legislación cubana e identificado en un registro de casas particulares, una actividad de alojamiento por la que pagan un determinado canon por habitación.

Por otra parte, también descansa en factores relacionados con las infraestructuras constructivas y del patrimonio inmobiliario, pues la exigencia de la preservación de los edificios se hace realidad en el caso de Cienfuegos $-\mathrm{y}$, en general, en todas las ciudades cubanas Patrimonio de la Humanidad-, porque la explotación turística garantiza la conservación de los inmuebles y de los valores arquitectónicos que encierran, dado que mantener los edificios en buenas condiciones es una exigencia para su explotación, en un contexto en que es muy costosa su preservación por la carestía e insuficiencia de los materiales de construcción.

Desde una perspectiva social, la actividad turística de Cienfuegos se ofrece como ejemplo de lo que pudiera considerarse una práctica sostenible para la conservación del patrimonio urbano, en correspondencia con los Objetivos de Desarrollo Sostenible, dado que es crucial para vincular estabilidad social e identidad. La mayor parte de los pequeños empresarios turísticos entrevistados hacían gala de los valores arquitectónicos del inmueble que ofrecían a los visitantes, manifestando también su orgullo por los bienes patrimoniales de su ciudad. Ello permitió apreciar, además, la estrecha relación que mantenían con los huéspedes alojados en estas viviendas, o en otras preservadas para el hospedaje exclusivo, pero con un contacto próximo con los anfitriones, favoreciendo la integración de los turistas en la cultural local, es decir, que no se limitaba a la visita a sitios y monumentos históricos, sino que los hacía partícipes de la forma de vida de los ciudadanos de Cienfuegos, una práctica que podría ser encuadrada en lo que ha sido definido por algunos autores como turismo naranja.

Finalmente, no cabe duda de la importancia de los valores patrimoniales que caracterizan a la ciudad de Cienfuegos: a) su trama ordenada y su simetría que, desde un punto de vista urbanístico la convierten en una ciudad modélica del canon clásico; b) sus edificios de orden neoclásico y ecléctico, un ejemplo de los presupuestos de la arquitectura decimonónica, propios de una etapa de esplendor colonial vinculada al negocio del azúcar y a la incipiente industrialización que vive la ciudad gracias a su puerto; c) las manifestaciones del estilo internacional, aunque escasas, representativas de la influencia norteamericana de la década de los años cincuenta del siglo xx y d) la capacidad de resiliencia de la sociedad cubana, gracias a la actividad turística, en un contexto internacional adverso. Todos estos elementos permiten interpretar la importancia que encierran los modestos establecimientos turísticos que velan por el patrimonio urbano en la ciudad de Cienfuegos, el objeto de estudio de esta investigación.

\section{REFERENCIAS}

Acerenza, M. A. (2000): Administración del Turismo. Planificación y Dirección. Volumen II, Editorial Trillas, México. 
Almeida, F. (2006): «Tipología de visitante turístico y satisfacción de la experiencia turística en Santiago de Compostela», Baética. Estudios de Arte, Geografía e Historia, 28: 231-258. http:/ / dx.doi.org/10.24310/BAETICA.2006.v1i28.260.

Antúnez SÁnchez, A.F.; Martínez Cumbrera, J.M.; Ocaña BÁez, J.L. (2013): «El Trabajo por Cuenta Propia. Incidencias en el nuevo relanzamiento en la aplicación del Modelo Económico de Cuba en el siglo XXI», Nómadas. Revista Crítica de Ciencias Sociales y Jurídicas. Núm. Especial América Latina: 97-118. https://doi.org/10.5209/rev_NOMA.2013.42344.

Boullón, R. (1997): Planificación del Espacio Turístico, Editorial Trillas, México.

BRITO, L.M. (2010): «El desarrollo urbano de Cienfuegos: presencia de los franceses», Universidad y Sociedad, 2 (3): 1-10.

Caballero Pérez, J.A. (2016): Registro de Obras del Movimiento Moderno en la Región Central de Cuba. Sancti Spíritus, Villa Clara, Cienfuegos, Tesis doctoral inédita, Universidad Central Marta Abreu de Las Villas, Facultad de Construcciones, Departamento de Arquitectura.

Callizo, J. (1991): A proximación a la Geografía del Turismo, Editorial Síntesis, Madrid.

Canales martínez, G.; SABARIEgos díAZ, J. (2011): "Trinidad, producto turístico integral y sostenible en Cuba», Cuadernos de Turismo, 27: 95-114.

Cañada, E.; Murray, I. (2019): «Introducción. Perspectivas críticas en turismo», en E. Cañada e I. Murray (eds.), Turistificación global. Perspectivas críticas en turismo, Icaria, Barcelona: 7-34.

Cardet, E.; González, Y.; Palao, R.I.; Puente, E. (2017): «Turismo y patrimonio a favor del desarrollo local, para diferenciar el destino Holguín", Retos Turísticos, 16 (1).

Chaos, M. T.; Arnaíz, M.A.; Falls, D.; SóÑorA, B. (2019): «El patrimonio urbanoarquitectónico, un atractivo turístico de los destinos patrimoniales», Uniandes Episteme, 6 (2): 291-305.

Coles, T.; Hall, M.; Duval. D. (2016): «Tourism and Postdisciplinarity: Back to the Future?», Tourism Analysis, 21 (4): 373-387. https://doi.org/10.3727/108354 216X14679788636113

Dodds, R.; Dimanche, F.; SAdowski, M. (2018): Planning for Growth in Islands: The Case of Cuba, Ryerson University, Toronto.

FABREgAt, G. (2014): «Experiencias en el tema ambiente - salud en la provincia de Cienfuegos, Cuba», Revista Pegada, 15: 65-91.

Ferrer Llanes, S. (2018): La arquitectura doméstica de madera en Cienfuegos, Tesis doctoral inédita, Universidad Central Marta Abreu de Las Villas, Facultad de Construcciones, Departamento de Arquitectura.

GARCíA, A. (2019): «La criolla y neoclásica vivienda cienfueguera del siglo XIX», La Jiribilla, 854 .

Gaynoso, A. (2004): «El papel de la Pequeña y Mediana Empresa en el futuro de Cuba», en J. Pujol (ed.), Cuba: Políticas económicas para la transición. Editorial Verbum, Madrid.

Guzmán, P.C.; Pereira, A.R.; Colenbrander, B.J.F. (2017): «Measuring links between cultural heritage management and sustainable urban development: An overview of global monitoring tools, Cities, 60, Part A: 192-201.

Jafari, J. (2005): «El turismo como disciplina científica», Política y Sociedad, 42 (1): 39-54.

JariwalA, S.A. (2014): «Cuban Housing Privatization: A Comparative Perspective on the Future of Housing in Havana, Cuba», CUREJ: College Undergraduate 
Research Electronic Journal, University of Pennsylvania. http://repository. upenn.edu/curej/184

López-Guzmán, T.; Prada-Trigo, J.; Pérez-Gálvez, J.; Pesantez, S. (2017): «El patrimonio inmaterial de la humanidad como herramienta de promoción de un destino turístico», Estudios y perspectivas en turismo, 26 (3): 568-584.

Matus, C.; ZúÑIgA-Becerra, P.; Pérez-Bustamante, L. (2019): «Patrimonialización de sitios industriales textiles: Más de una década de puesta en valor por las comunidades de Tomé», Sophia Austral, 23: 235-256

Munar, A.M.; Pernecky, T.; Feighery, W. (2016): «An Introduction to Tourism Postdisciplinarity», Tourism Analysis, 21 (4): 343-347. https://doi.org/10.372 7/108354216X14600320851578

Organización Mundial del Turismo (OMT) (2007): A Practical Guide to Tourism Destination Management, Organización Mundial del Turismo, Madrid.

Pearce, D. (2013): "Gestión de destinos turísticos en hinterlands costeros y urbanos», Revista Geográfica de Valparaíso, 48: 57-73.

Pérez Albert, Y.; Nello Endreu, M. (2013): «Propuesta de indicadores para evaluar la sostenibilidad de la actividad turística. El caso del Valle de Viñales (Cuba)», Anales de Geografía de la Universidad Complutense, 33 (1): 193-210. https://doi.org/10.5209/rev_AGUC.2013.v33.n1.42225

Pérez Guilarte, Y. (2015): «La imagen del turismo cultural en Cuba percibida por el mercado español», Revista Turismo y Sociedad, 16: 67-84. https://doi. org/10.18601/01207555.n16.05

PONCE, G. (2010): «Las ciudades patrimoniales cubanas como producto turístico», Investigaciones Geográficas, 52: 137-166.

Rivero, Á.B.; KunA, G. (2013): «Turismo Patrimonial. Fundamentos y Debates», ARGOS. Universidad Nacional de Misiones, Posadas.

Rodríguez Alomá, P.; Fornet Gil, P.; León Candelario, I.; Zamora Rielo, R. (2014): Luces y simientes. Territorio y gestión en cinco centros históricos cubanos. Red de las Oficinas del Historiador y el Conservador de las ciudades patrimoniales de Cuba, La Habana.

Rodríguez, G.; CAMAcho, A. (2017): «Estudios del patrimonio cultural de uso turístico en la región central de Cuba», Islas, 59 (187): 83-90.

Rodríguez, R.; Moreno, X.; SAn Marful, E. (2018): «Population and demographic dynamics in Cienfuegos province, Cuba», Revista Novedades en Población, 14 (27): 1-11.

Rovira GonzÁlez, V.; Olite Montesbravo, M.E. (1976): Cienfuegos durante la República Neocolonial (1902-1935), Empresa Nacional de Producción del Ministerio de Educación Superior, La Habana.

SAcchettI, E. (2011): Vivir en la cuerda floja. La Microempresa en Cuba, Editorial Académica Española, Madrid.

Salinas, E.; Delgado, F.A.; Henthorne, T.; Miller, M. (2018): «The Hershey sugar mill in Cuba: from global industrial heritage to local sustainable tourism development», Journal of Heritage Tourism, 13 (5): 426-439. https:/ / doi.org/1 0.1080/1743873X.2017.1391270.

SERAPHIN, H.; GladKIKH T.; Vo ThanH, T., eds. (2020): Overtourism. Causes, Implications and Solutions, Palgrave Macmillan, London. https://doi.org/10.1007/978-3030-42458-9

Silveira, Y.; CABeZA, D.; FernáNDEZ, V. (2016): «Emprendimiento: perspectiva cubana en la creación de empresas familiares», European Research on 
Management and Business Economics, 22 (2): 70-77. https://doi.org/10.1016/j. iedee.2015.10.008.

StUcKI, A. (2017): Las guerras de Cuba: Violencia y campos de concentración (18681898), La Esfera de los Libros, Madrid.

Troitiño-Vinuesa, M.A.; Troitiño-Torralba, L. (2016): «Patrimonio y turismo: reflexión teórico-conceptual y una propuesta metodológica integradora aplicada al municipio de Carmona (Sevilla, España)», Scripta Nova, 20 (543):145. https://doi.org/10.1344/sn2016.20.16797.

Troitiño-VinuesA, M.A. (2018): «Las Ciudades Patrimonio de la Humanidad de España: El desafío de Destinos Turísticos Sostenible en clave de Patrimonio Cultural», Estudios Turísticos, 216: 27-54.

Valls, J. F., Bustamante, X., Guzmán, F., y Vila, M. (2004): Gestión de destinos turísticos sostenibles, Gestión 2000, Barcelona.

Young, T., Witsel, M., y Boyle, A. (2017): «Special Issue: Critical perspectives in hospitality, leisure, sport and tourism education», Journal of Hospitality, Leisure, Sport and Tourism Education, 21(B): 123-204. 
